\title{
Interfacial Shear Rheology of -Lactoglobulin - Bovine Submaxillary Mucin Layers Adsorbed at Air/Water Interface
}

\author{
Celebioglu, Hilal Yilmaz; Kmiecik-Palczewska, Joanna; Lee, Seunghwan; Chronakis, loannis S.
}

Published in:

International Journal of Biological Macromolecules

Link to article, DOI:

10.1016/j.ijbiomac.2017.04.063

Publication date:

2017

Document Version

Peer reviewed version

Link back to DTU Orbit

Citation (APA):

Celebioglu, H. Y., Kmiecik-Palczewska, J., Lee, S., \& Chronakis, I. S. (2017). Interfacial Shear Rheology of Lactoglobulin - Bovine Submaxillary Mucin Layers Adsorbed at Air/Water Interface. International Journal of Biological Macromolecules, 102, 857-867. https://doi.org/10.1016/j.jibiomac.2017.04.063

\section{General rights}

Copyright and moral rights for the publications made accessible in the public portal are retained by the authors and/or other copyright owners and it is a condition of accessing publications that users recognise and abide by the legal requirements associated with these rights.

- Users may download and print one copy of any publication from the public portal for the purpose of private study or research.

- You may not further distribute the material or use it for any profit-making activity or commercial gain

- You may freely distribute the URL identifying the publication in the public portal 


\section{Accepted Manuscript}

Title: Interfacial Shear Rheology of $\beta$-Lactoglobulin - Bovine Submaxillary Mucin Layers Adsorbed at Air/Water Interface

Authors: Hilal Y. Çelebioğlu, Joanna Kmiecik-Palczewska, Seunghwan Lee, Ioannis S. Chronakis

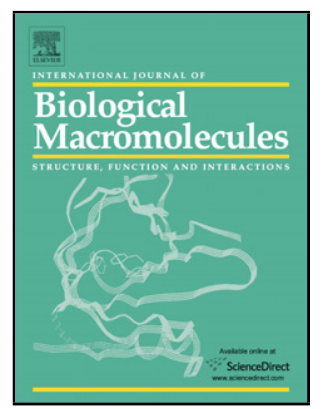

PII:

S0141-8130(17)30595-0

DOI: http://dx.doi.org/doi:10.1016/j.ijbiomac.2017.04.063

Reference: BIOMAC 7427

To appear in: International Journal of Biological Macromolecules

Received date: $16-2-2017$

Revised date: 25-3-2017

Accepted date: $15-4-2017$

Please cite this article as: Hilal Y.Çelebioğlu, Joanna Kmiecik-Palczewska, Seunghwan Lee, Ioannis S.Chronakis, Interfacial Shear Rheology of $\beta$-Lactoglobulin - Bovine Submaxillary Mucin Layers Adsorbed at Air/Water Interface, International Journal of Biological Macromoleculeshttp://dx.doi.org/10.1016/j.ijbiomac.2017.04.063

This is a PDF file of an unedited manuscript that has been accepted for publication. As a service to our customers we are providing this early version of the manuscript. The manuscript will undergo copyediting, typesetting, and review of the resulting proof before it is published in its final form. Please note that during the production process errors may be discovered which could affect the content, and all legal disclaimers that apply to the journal pertain. 


\title{
IJBIOMAC_2017_538- Revised
}

\section{Interfacial Shear Rheology of $\beta$-Lactoglobulin - Bovine Submaxillary Mucin Layers Adsorbed at Air/Water Interface}

\author{
Hilal Y. Çelebioğlu, ${ }^{1}$ Joanna Kmiecik-Palczewska, ${ }^{1,2}$ Seunghwan Lee, ${ }^{3}$ and \\ Ioannis S. Chronakis ${ }^{1 *}$
}

\footnotetext{
${ }^{1}$ Nano-BioScience Research Group, DTU-Food, Technical University of Denmark, Søltofts plads, building 227, 2800 Kgs. Lyngby, Denmark.

${ }^{2}$ Poznan University of Technology, Institute of Chemical Technology and Engineering, Department of Chemical Engineering and Equipment,. ul. Berdychowo 4, 60-965 Poznan, Poland

3 Department of Mechanical Engineering, Technical University of Denmark, DK-2800 Kgs. Lyngby, Denmark
}

*Corresponding author: Tel: +45 40206413, e-mail: ioach@food.dtu.dk 


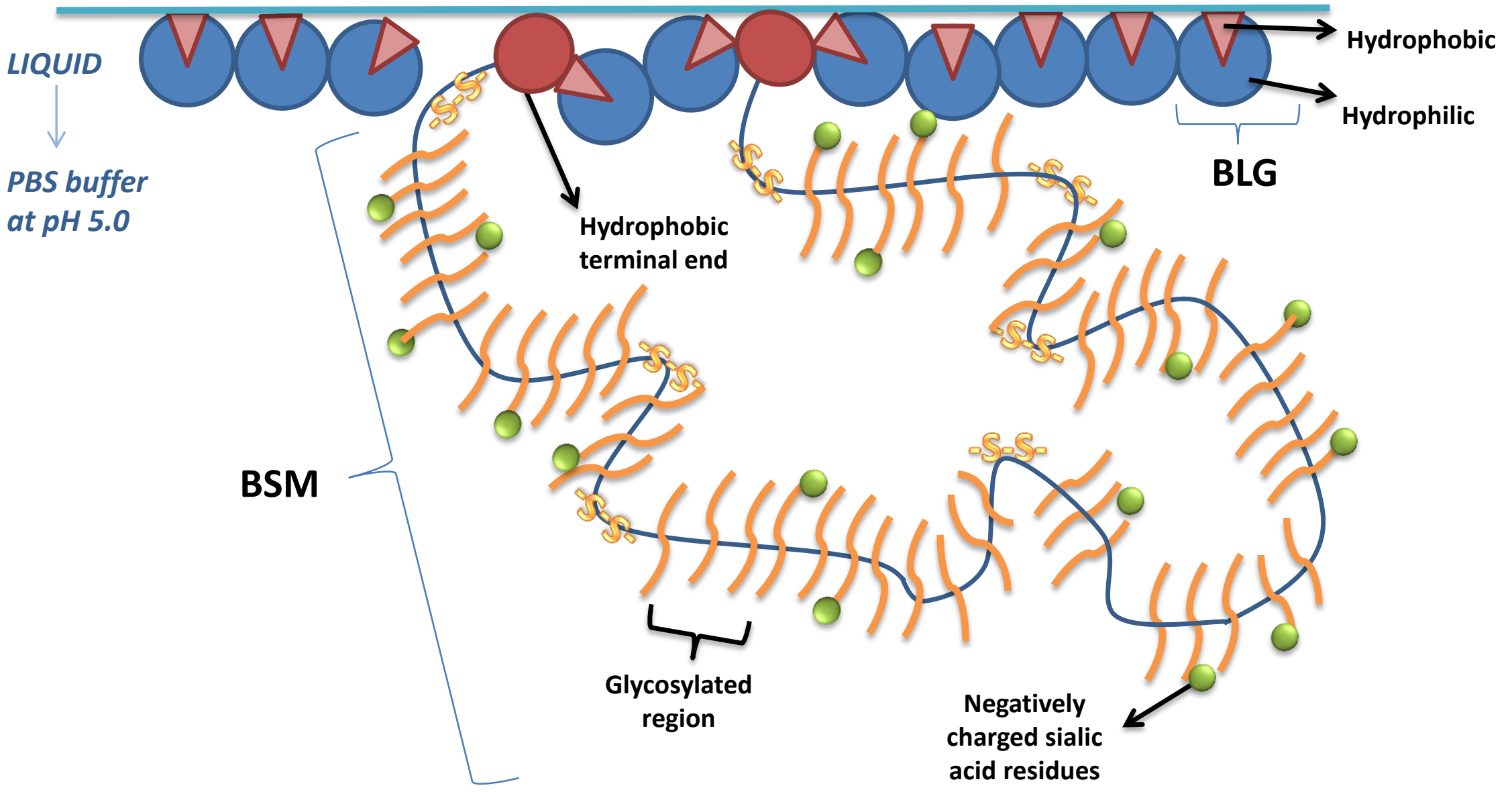




\section{Highlights}

- The interfacial rheological properties of solutions of BLG (as a model food compound) with a salivary mucin protein BSM and their mixtures, at different pHs were studied.

- BLG molecules move faster for their smaller size/mass than mucins, and dominate the surface adsorption and the network formation for the BLG-BSM mixtures.

- BSMs decreased the surface viscoelasticity and the rigidity of the BLG layers through the penetration of the hydrophobic parts of BSM between the adsorbed BLG molecules and disorder their cohesive assembly, which was most pronounced at $\mathrm{pH} 5$. 


\begin{abstract}
The interfacial rheological properties of solutions of $\beta$-lactoglobulin (BLG), as a model food compound, mixed with bovine submaxillary mucin (BSM), a major salivary protein, have been investigated. Time, frequency, stress sweep and flow measurements have been performed at different $\mathrm{pHs}(7.4,5.0$ and 3.0), to investigate the air/water interfacial properties. All protein layers (BLG, BSM, and BLG-BSM mixtures) formed an elastic network at the air/water interface with low frequency dependence of the interfacial modulus. The results indicated that BLG moves faster as smaller molecule than mucin, and dominate the surface adsorption and the network formation for the BLG-BSM mixtures. Moreover, BLG-BSM protein mixtures exhibited interfacial properties with lower elastic and viscous moduli than BLG, as a result of competitive displacement of BLG proteins with BSMs from the interface. It is suggested that hydrophobic patches of BSM can be imbedded into the BLG monolayer as driven by a strong hydrophobic interaction with air and disrupt the cohesive assembly of BLG, whereas the hydrophilic (negatively charged) parts of the BSM chain are protruding from the interface towards the bulk water.
\end{abstract}

Keywords: Interfacial shear rheology, $\beta$-lactoglobulin, bovine submaxillary mucin 


\section{Introduction}

Beta-lactoglobulin (BLG) is a milk protein widely used as functional ingredient for the formation and stabilization of food emulsions and foams [1-3], due to its ability to adsorb rapidly at the surface and stabilize colloidal systems [4]. BLG is the major whey protein, constituting $>50 \%$ of the total whey proteins in bovine milk, with a molecular weight of $18.3 \mathrm{kDa}$ and a radius of approximately $2 \mathrm{~nm}$ [5]. On the other hand, bovine submaxillary mucin (BSM), used as a model mucin in this study, is a glycoprotein consisting of a linear polypeptide core with a highly glycosylated central part accounting for up to $80 \%$ of the proteins molecular weight [6] which ranges between 0.5 and $20 \mathrm{MDa}$ [7]. Among several types of mucin involved, submaxillary mucin is the one most closely related to oral processing.

The interaction between a model food protein, BLG, and saliva protein, bovine submaxillary mucin (BSM), has been investigated by different techniques, including nuclear magnetic resonance, dynamic light scattering, circular dichroism, in our recent study [8]. The main findings are: (i) An attractive interaction between the two proteins was suggested. (ii) Higher hydrophilic interactions between the proteins at lower $\mathrm{pH}$ supported the $\mathrm{pH}$ dependent activity of both BLG and BSM. (iii) The positively charged groups of BLG, especially at acidic pHs, neutralized negatively charged groups of BSM and caused the BSM to coil or contract into a smaller hydrodynamic volume [8, 9]. (iv) Even a weak hydrogen bonding between BLG and BSM, promotes aggregation of mucins into a more compact structure at $\mathrm{pH}$ 7.4. (v) NMR studies showed that negatively charged BLG has a tendency to interact with negatively charged mucin via secondary interactions (hydrogen bonding and hydrophobic effects), where the electrostatic interactions are unlikely to be the main reason of the binding. 
Another recent study [10] based on bicinchoninic acid (BCA) protein qualification assay showed that mucins were not only higher than BLG in the adsorbed masses onto the solid hydrophobic surface, but also adsorb in a more compact conformation due to a high flexibility to accommodate themselves in a narrow space and/or possibly to form multilayers. However, BLG can readily dominate the initial stage of surface adsorption at the solid/water interface in the solution mixture of BSM and BLG, due to the ability of the smaller and lighter BLG molecules to reach the surface faster than mucins. For the adsorption of the BLG-BSM mixture onto hydrophobic solid surfaces, it was assumed that there is a large portion of "free" BLG molecules in the mixed protein solutions, and that they participate in the surface adsorption process in competition with the mucins. Consequently, the BSM, BSM and their mixtures showed an interesting interaction and different surface adsorption behavior at the solid/liquid interface. However, the interfacial properties of BLG, BSM, and their mixtures at air/liquid interface were not studied to date despite their high relevance and significance to the formation of emulsion and foams.

Furthermore, interfacial shear rheology provides valuable information on the intermolecular interaction processes and structural changes of interfacial layers at the air/liquid interface [11]. The interfacial shear rheology is based on the functional relationship between stress, deformation and the rate of deformation at an interface in terms of elastic modulus $\left(G_{i}{ }^{\prime}\right)$ and viscous modulus $\left(G_{i}{ }^{\prime \prime}\right)$ [12]. The interfacial rheological properties are less sensitive to Marangoni stresses and dynamic surface tension but more sensitive to intermolecular interactions between adsorbed molecules [13]. Hence, such properties are valuable to study protein interactions, in particular the adsorption of large molecular weight proteins (i.e. mucins) which have slow and irreversible adsorption process, and Marangoni stresses at which dynamic surface tension effects are suppressed [14]. It is to note that proteins at the interface interact through physical interactions such as electrostatic, hydrophobic as well as van der Waals forces. 
The interfacial shear rheology of BLG has been studied as a function of heat treatment, $\mathrm{pH}$ dependence and ionic strength. For example, Jung, Gunes, \& Mezzenga [15], Kim, Cornec, \& Narsimhan [16], Roth et al. [17], and Rühs et al. [3] suggested that BLG is able to develop a strong and rapid viscoelastic layer at the air/water interface, which is strongest at its isoelectric point (pI 5.4) due to the lowest net charge and due to the presence of a more strongly cross-linked protein network at the interface. Meanwhile, to the best of our knowledge, only one study is available in the literature related to the interfacial rheological properties of saliva and astringent compounds by Rossetti et al. [13], who have studied the interfacial behavior of pig gastric mucin and bovine submaxillary gland mucin in comparison with the saliva. They have observed that these mucins do not form a strong protein network, as indeed shown by the human saliva at the air/water interface.

Moreover, it is important to understand the interfacial rheological properties of adsorbed BLG and BSM mucin layers and their network formation at the air/liquid interface, as this is relevant in understanding the interactions between (dairy) emulsions and saliva, and thus in understanding emulsion perception. In this study, the air/water interfacial rheological properties of solutions of BLG with a salivary BSM mucin protein, and their mixtures at different $\mathrm{pHs,} \mathrm{were} \mathrm{investigated.}$ 


\section{Materials and methods}

\subsection{Sample preparation}

BLG from bovine milk and BSM (Type I-S) were purchased from Sigma Aldrich (Sigma Aldrich A/S, Brøndby, Denmark), and were used as received. Protein solutions with the concentration of 1 $\mathrm{mg} / \mathrm{mL}$ were prepared by dissolving proteins in $10 \mathrm{mM}$ phosphate buffered saline (PBS) solutions. The $\mathrm{pH}$ values of the buffer solutions were adjusted to $7.4,5.0$, and 3.0 by the addition of $\mathrm{HCl}$ or $\mathrm{NaOH}$ as appropriate. For the mixtures of BSM and BLG, the two protein solutions were mixed at the ratio of $1: 1(\mathrm{v}: \mathrm{v})$, while the final concentrations of the total proteins were set at $1 \mathrm{mg} / \mathrm{mL}$ or 2 $\mathrm{mg} / \mathrm{mL}$. The concentration of $1 \mathrm{mg} / \mathrm{mL}$ was used for the first mixture (MIX 1) where each protein (BLG and BSM) has $0.5 \mathrm{mg} / \mathrm{mL}$ in concentration. The second mixture (MIX 2) was prepared with 1 $\mathrm{mg} / \mathrm{mL}$ concentration of each proteins (BLG and BSM), hence with $2 \mathrm{mg} / \mathrm{mL}$ in total protein concentration.

\subsection{Interfacial shear experiments}

In the present study, a bi-conical disc was used, where the edge of the bi-cone bob was located at the interface of a liquid sample (air/liquid interface). The outer cup is stationary and the bi-conical geometry acts as "two-dimensional concentric cylinder geometry" [18]. Further details about the instrumental setup of the bi-cone rheometer can be found in the litterature [19].

A Physica MCR 302 rheometer with a Peltier temperature device (P-PTD 200/80I) and the Interfacial Rheology System (IRS) accessory with the bi-cone (BiC68-5) geometry from Anton Paar (Graz, Austria) were used for all the experiments. The bi-cone geometry had a diameter of 68.32 
$\mathrm{mm}$ and the angle was $10^{\circ}\left(2 \times 5^{\circ}\right)$. Time sweep measurements were performed with a constant frequency $(6.28 \mathrm{rad} / \mathrm{s})$ and an amplitude gamma (strain) of $0.02 \%$ during 150 minutes. Then, $G_{i}{ }^{\prime}$ and $G i^{\prime \prime}$ were measured in angular frequency from initial $100 \mathrm{rad} / \mathrm{s}$ to final $0.01 \mathrm{rad} / \mathrm{s}$ with amplitude gamma of $0.02 \%$. After that, strain sweeps were obtained using a constant frequency of $6.28 \mathrm{rad} / \mathrm{s}$. Finally, flow measurements were performed while changing the shear rate from $0.1 \mathrm{~s}^{-1}$ to $300 \mathrm{~s}^{-1}$. All measurements were performed at $20^{\circ} \mathrm{C}$. 


\section{Results \& Discussions}

\subsection{Time dependence of the interfacial modulus}

Initially, the interfacial linear viscoelastic properties of the proteins were measured as a function of time. The time dependencies of the interfacial shear elastic modulus $G_{i}{ }^{\prime}$ and viscous modulus $G_{i}{ }^{\prime \prime}$ for BLG, BSM and for the BSM-BLG mixtures at different $\mathrm{pH}$ values are shown at Fig. 1. The results indicate that all the proteins adsorbed immediately and formed a stable viscoelastic network at the air/water interface with $G_{i}{ }^{\prime}>G_{i}{ }^{\prime \prime}$ with a formation of a plateau within 50 min.

Clearly, BLG molecules had higher elastic modulus than the BSM and the BLG-BSM mixtures, indicating that the BLG formed a stronger viscoelastic adsorption layer at all $\mathrm{pH}$ conditions. The elastic modulus of BLG was about $0.02,0.2$, and 0.035 Pa.m at $\mathrm{pH} 3.0,5.0$, and 7.4, respectively. Thus, BLG had relatively higher values of $G_{i}{ }^{\prime}$ and $G_{i}{ }^{\prime \prime}$ at the $\mathrm{pH}$ close to the isoelectric point of the protein $(\mathrm{pH}=\sim 5.2)$. This is in agreement with previous studies for BLG and for other proteins, suggesting that in the absence of electrostatic repulsive interactions at their isoelectric $\mathrm{pH}$, the proteins experience mainly attractive interactions at the interface leading to aggregation and network formation [17] [20] [21] [22] [23]. The increase of the electrostatic repulsions of the protein at $\mathrm{pH} 7.4$ and $\mathrm{pH} 3$ could be responsible for the lower viscoelastic interactions and lower interfacial modulus in comparison with the modulus of the protein at $\mathrm{pH} 5$, as also suggested in previous studies [24][25][3].

BSM molecules formed weak viscoelastic networks immediately; the elastic and viscous modulus values remain nearly constant regardless of $\mathrm{pH}$ changes (Fig. 1). This weak viscoelastic network was destroyed easily even at low strain values $(\geq 0.03 \%$, see below). The lack of strong interfacial viscoelasticity of BSM was also shown in the study Rossetti et al. [13]. They have compared commercial mucins (pig gastric mucin and bovine sub-maxillary gland type I mucin from Sigma 
Aldrich) with the human whole saliva and concluded that the commercial mucin did not fully mimic the interfacial properties of human whole saliva, possibly due to the degradation of the gel-like structure occurred during the isolation process.

The interfacial rheological properties of the BLG and BSM mixtures are also shown in Fig. 1. The values of the elastic and viscous modulus for both BLG-BSM mixtures (MIX 1 and MIX 2) were between those of neat BLG and BSM. Both $G_{i}{ }^{\prime}$ and $G_{i}{ }^{\prime \prime}$ of the MIX 1 and MIX 2 at pH 5 and pH 3 were decreased during the first 60 minutes to reach a plateau, while they were almost stable at $\mathrm{pH}$ 7.4 during 150 minutes of time (Fig. 1). These results indicate that the interfacial layer of the protein mixtures is formed mainly through the adsorption of the interfacial active BLG molecules, with the additional incorporation of BSM molecules within the surface layer, which retard and diminish the interfacial network modulus. Note that MIX 2 has slightly higher modulus at $\mathrm{pH} 7.4$, but lower modulus at $\mathrm{pH} 5.0$ and $\mathrm{pH} 3.0$, than the MIX 1.

The $\mathrm{pH}$ dependent changes of the elastic modulus $\left(G_{i}{ }^{\prime}\right)$ of BLG, BSM and BLG-BSM mixtures with different protein concentrations is shown at Fig. 2a. In particular, the values of the elastic modulus were utilized for the evaluation of the interaction between the BLG and BSM [26], by using the interaction term $\Delta G_{i}{ }^{\prime}$ :

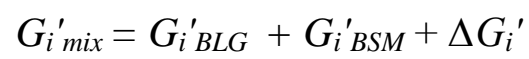

where $G_{i}{ }^{\prime}{ }_{m i x}$ is the elastic modulus of the mixture and $G_{i}{ }^{\prime}{ }_{B L G}$ and $G_{i}{ }^{\prime}{ }_{B S M}$ represent the elastic modulus of BLG and BSM, respectively (Fig. 2a). 
The above results showed that BSM caused a decrease of the elastic modulus of the BLG-BSM mixtures, and that the interfacial properties of the protein mixtures have similar $\mathrm{pH}$-dependent properties with the BLG. Consequently, for the BLG-BSM mixtures it is reasonable to suggest that BLG is the dominant interfacial active molecule due to its capability to adsorb fast and form an interfacial network, while the presence of long BSM chains rather disrupts it. This is in agreement with a previous study by Dickinson [27] where in the case of the competitive adsorption between proteins, the adsorbed layer is dominated by the protein that adsorbed first to the interface. In our recent tribology study, we have also observed that BLG dominates the surface adsorption at water/hydrophobic (solid surface) interfaces, and at $\mathrm{pH} 5.0$ the adsorbed amount is roughly double to those at pH 3.0 and 7.4 [10]. Hägerström et al [26] also found that bovine submaxillary gland mucin destroyed the interfacial network structure of the absorbed deacetylated gellan gum. Danov et al [28] observed the same phenomena for the interfacial properties of active globular protein hydrophobin (HFBII) and the disordering protein $\beta$-casein. They showed that the disordering protein decreases the rigidity of the HFBII adsorption layers, due to the penetration of long hydrophobic chains of $\beta$-casein between the adsorbed HFBII molecules, as driven by the favorable hydrophobic interaction between the chains and air.

The negative interaction term $\Delta G_{i}{ }^{\prime}$ at each $\mathrm{pH}$ values denotes the extent of the reduction of the interfacial network of the protein mixtures (Fig. 2a). Note that the values of $\Delta G_{i}{ }^{\prime} 1$ and $\Delta G_{i}{ }^{\prime 2}$ were similar at each $\mathrm{pH}$ despite that the protein concentration was two times higher for the MIX 2. This could be due to that the large molecular weight BSM effectively disrupts the viscoelastic layer of BLG and limit the stability of the interfacial network even at lower concentrations (e.g. that of MIX 1). Moreover, the values of $\Delta G_{i}{ }^{\prime}$ showed maxima at $\mathrm{pH} 5.0$, which indicates that the disruption of BLG layer by BSM is most effective at this $\mathrm{pH}$ condition. This is readily understandable for the case of $\mathrm{pH}$ 7.4, where both BLG and BSM were negatively charged, and thus BSM molecules may 
be repelled in approaching to the interface. However, at $\mathrm{pH} 3.0, \mathrm{BLG}$ and BSM molecules are oppositely charged and even hydrogen bonding were observed to be activated [8]. Thus, BSM molecules may have a stronger attraction with the BLG layer formed at $\mathrm{pH}$ 7.4. Nevertheless, since both electrostatic and hydrogen bonding are hydrophilic characteristics, it would be predominantly the hydrophilic moieties, (e.g. central glycosylated regions of BSM), that are interacting with the BLG layer and the interaction would be limited within the water phase. Moreover, the increase of the electrostatic repulsions of the BLG molecules at $\mathrm{pH} 7.4$ and $\mathrm{pH} 3$ could be responsible for the lower interfacial modulus and the lower viscoelastic interactions of BLG with BSM, in comparison with the interactions found at $\mathrm{pH} 5$ (Fig. 3). Thus, disruption of the BLG layer would be limited accordingly. On the contrary, at $\mathrm{pH}$, the interaction of the hydrophobic patches of BSM with the BLG layer maybe particularly facilitated due to the non-polar characteristics of the BLG layer. Such interactions can be further extended at the air/water interphase and disrupt effectively the BLG layer, as illustrated at Fig. 3.

Similar trends of the interfacial properties were also observed for the viscous modulus $G_{i}{ }^{\prime \prime}{ }_{m i x}$ of the mixture when correlated with $G_{i}{ }^{\prime \prime}{ }_{B L G}$ and $G_{i}{ }^{\prime \prime}{ }_{B S M}$ (the viscous modulus of BLG and BSM) and the term $\Delta G_{i}{ }^{\prime \prime}$ (Fig. 2b).

\subsection{Frequency dependence of the interfacial modulus}

Fig. 4 shows the changes of the $G_{i}{ }^{\prime}$ and $G_{i}{ }^{\prime \prime}$ as a function of angular frequency for BLG, BSM, MIX 1 and MIX 2 at different $\mathrm{pH}$ values. The values of the elastic modulus $G_{i}{ }^{\prime}$ were greater than the viscous modulus $G_{i}{ }^{\prime \prime}$ for all the protein samples suggesting that they exhibited mainly elastic-like behavior within a frequency range from $0.01 \mathrm{rad} / \mathrm{s}$ to $10 \mathrm{rad} / \mathrm{s}$. Moreover, the interfacial modulus 
were increased with the frequency, with different slopes and both moduli were described by the power law equation:

$G_{i}{ }^{\prime}=k^{\prime} \omega^{m^{\prime}}$

$G_{i}^{\prime \prime}=k^{\prime} \omega^{m \prime}$

The values of constants $k^{\prime}$ and $k^{\prime \prime}$ and slopes $m^{\prime}$ and $m^{\prime \prime}$ are shown in Table 1 .

The elastic modulus $G_{i}{ }^{\prime}$ of BSM had lower slopes than the elastic modulus $G_{i}{ }^{\prime}$ of BLG at each $\mathrm{pH}$ values (Table 1), i.e. BSM molecules were less frequency dependent and with low elastic modulus. The slopes $\left(\mathrm{m}^{\prime}\right)$ of BLG-BSM mixtures showed similar values at $\mathrm{pH} 7.4$ and 3.0 and were low, while the slopes at $\mathrm{pH} 5.0$ were higher and close to the slope of BLG. The similarities of the frequency sweeps of the BLG-BSM mixtures with that of BLG also support the above suggestion that BLGs move faster as smaller molecules than mucins, and dominate the surface adsorption, the network formation and stability in the BLG-BSM mixtures.

Frequency dependent changes in the interfacial complex $\left(\eta_{i}{ }^{*}\right)$ and interfacial steady-shear $\left(\eta_{i}\right)$ viscosities of all protein samples at $\mathrm{pH} 7.4, \mathrm{pH} 5.0$ and $\mathrm{pH} 3.0$ are shown in Fig. 5. Clearly the interfacial complex viscosity of the MIX 2 was significantly higher than the interfacial steady-shear viscosity at each $\mathrm{pH}$ values; this suggests that the protein samples deviate from the Cox-Merz rule (at which the complex dynamic viscosity $\left(\eta^{*}\right)$ and the steady-shear viscosity $(\eta)$ superimpose at equivalent numerical values of frequency and shear rate). The higher values of the interfacial complex viscosity in comparison with the interfacial steady-shear viscosity, indicates that the interfacial structure of the BLG-BSM mixture was easier to be deformed in the steady state flow 
than in the oscillatory shear. This type of behavior is characteristic for high-density entangled or aggregated structures [29] and provides additional evidences that an associated BLG-BSM interfacial network was formed.

\subsection{Strain dependence of the interfacial modulus}

Fig. 6 shows the results of strain sweeps for BLG, BSM and the mixtures at pH 7.4, 5.0 and 3.0. The both moduli were described by the power law equation:

$G_{i}{ }^{\prime}=c^{\prime} \gamma^{n^{\prime}}$

$G_{i}^{\prime \prime}=c^{\prime \prime} \gamma^{n^{\prime \prime}}$

The values of constants $c^{\prime}$ and $c^{\prime \prime}$ and slopes $n^{\prime}$ and $n^{\prime \prime}$ are shown in Table 2 . In addition, Table 3 shows the crossover points of each sample.

According to the Fig. 6a, BLG at pH 7.4 has a well-established linear viscoelastic region up to 3\% of strain with 0.03 Pa.m of elastic modulus and 0.007 Pa.m of viscous modulus. At $25 \%$ of strain, the crossover point for the BLG samples was observed and each modulus started to decrease. The decrease of $G_{i}{ }^{\prime}$ of BLG was rapid with a slope of -1.22, while the decrease of $G_{i}{ }^{\prime \prime}$ was slower with a slope of -0.51. At pH 5.0, the BLG had higher values of $G_{i}{ }^{\prime}$ (ca. 0.11 Pa.m) and $G_{i}{ }^{\prime \prime}$ (ca.0.019 Pa.m) than at $\mathrm{pH} 7.4$, however the crossover point was reached at $6 \%$ of strain with higher slopes $(-2.06$ for $G_{i}{ }^{\prime}$ and -0.81 for $\left.G_{i}{ }^{\prime}\right)$. On the other hand, a lower modulus (0.02 Pa.m and 0.005 Pa.m for $G_{i}{ }^{\prime}$ and $G_{i}{ }^{\prime \prime}$, respectively) and weak elastic properties were observed at $\mathrm{pH} 3.0$, with similar crossover strain as at $\mathrm{pH} 5.0$ (Table 3). In contrast to BLG, BSM lost its weak linear viscoelastic network 
properties rapidly with increasing strain beyond $0.003 \%$ and then exhibited viscous behavior (Fig. $6)$.

In the case of the protein mixtures (MIX1 and MIX2), despite the presence of large BSM molecules, they exhibited a viscoelastic strain sweep behavior similar to BLG. The crossover point for the MIX 1 mixture was observed at ca. 37\%, 8\%, and 12\% strain at $\mathrm{pH} 7.4,5.0$, and 3.0, respectively. The slopes of the decrease of $G_{i}{ }^{\prime}$ was $-1.16,-1.86,-1.95$, similar to BLG, while the decrease of $G_{i}{ }^{\prime \prime}$ was lower than BLG with slopes of $-0.32,-0.72,-0.42$ at $\mathrm{pH} 7.4,5.0$ and 3.0, respectively.

These results also indicate that the BLG protein dominated the network formation and network stability for the BLG-BSM mixtures at $1 \mathrm{mg} / \mathrm{mL}$. The strain sweep of the MIX 2 (Fig. 6 and Table 2 and 3) showed similar elastic and viscous modulus and slopes with MIX 1 at $\mathrm{pH} 7.4$; however, the modulus of the MIX 2 was decreasing with a lower slope at $\mathrm{pH} 5.0$ than MIX 1. For instance, the slopes of $G_{i}{ }^{\prime}$ of MIX 2 were -1.29 and -1.27 , while they were -1.17 and -1.86 for MIX 1 at $\mathrm{pH} 7.4$ and $\mathrm{pH} 5.0$, respectively. At $\mathrm{pH} 3.0$ both the elastic and viscous moduli of the MIX 2, as well as the linear viscoelastic region were very narrow, close to BSM, with the crossover point at $0.40 \%$ of strain. This may suggest that the MIX 2 at pH 3.0 had a disrupted, non-stable interfacial network formation and lower modulus than MIX 1 due to the higher content of BSM (Table 3). The higher hydrophilic interaction between the proteins at $\mathrm{pH} 3.0$, as well as the increased electrostatic attraction between positively charged BLG and negatively charged BSM, as suggested at our previous study [8], most probably caused the BSM to be imbedded into the assembled BLG layer and destabilize the interfacial network.

Fig. 7 shows the $\tan \delta_{i}$ values as a function of strain for BSM, BLG and the mixtures of BSM-BLG. Tan $\delta_{i}$ is the ratio of $G_{i}{ }^{\prime \prime} / G_{i}{ }^{\prime}$, providing a convenient index of the proportion of the viscous-like 
character. The higher $\tan \delta_{i}$ values indicate a more viscous-like behavior while the lower values indicate a more elastic-like behavior. At all $\mathrm{pH}$ values, BLG showed lower $\tan \delta_{i}$ values with increased strain than the MIX 1 and MIX 2. BSM showed low tan $\delta_{i}$ values below the strain of $0.02 \%$ where the interfacial network disrupted suddenly. Moreover, MIX 2 exhibited higher $\tan \delta_{i}$ values at $\mathrm{pH} 3.0$, indicating the relative viscous-like behavior in comparison with the interfacial network at $\mathrm{pH} 7.4$ and 5.0. The increased electrostatic interaction between protein (positively charged BLG and negatively charged BSM) at $\mathrm{pH} 3.0$ resulted in the formation of a complex protein interfacial network with dominating BSM viscoelasticity.

\section{Conclusions}

We have studied the interfacial rheological properties of solutions of BLG (as a model food compound) with a salivary mucin protein BSM and their mixtures, at different pHs. All protein layers (BSM, BLG, MIX1 and MIX2) formed at air/water interface has some similarities such as a rapidly developed elastic interfacial network and low frequency dependence of the interfacial modulus.

The BSM protein with the high molecular weight formed a weak viscoelastic interfacial network (lower modulus) compared to BLG at all pHs, which is destroyed even at a low strain (0.003\%). The $\mathrm{pH}$ has a significant effect on the surface density of adsorbed BLG proteins, as it determines the net charges and the modulus of the interfacial network. At $\mathrm{pH}$ close to the isoelectric point, electrostatic repulsions between the adsorbed BLG molecules at the interface are minimized, promoting the formation of a stable adsorbed layer with a high elastic modulus.

Furthermore, BLG molecules move faster due to their smaller size/mass than mucins, and dominate the surface adsorption and the network formation of the BLG-BSM mixtures. However, BLG-BSM 
protein mixtures exhibited interfacial properties with lower elastic and viscous moduli than BLG, as a result of competitive displacement of BLG proteins with BSM molecules at the interface.

We propose that BSMs decreased the surface viscoelasticity and the rigidity of the BLG layers through the penetration of the hydrophobic parts of BSM between the adsorbed BLG molecules and disorder their cohesive assembly, which was most pronounced at $\mathrm{pH}$ 5.0. Moreover, it is to note that the facile attraction of BSM molecules towards BLG layer within water phase is not sufficient to activate this mechanism. At $\mathrm{pH} 3.0$, for example, despite the electrostatic attraction between the oppositely charged BSM and BLG layers, the reduction in the viscoelasticity and rigidity of the network is weaker compared to that at $\mathrm{pH}$ 5.0. This can be explained by the overall hydrophilic nature of their interactions that hinders the hydrophobic parts of BSM to disrupt the assembled layer of BLG and extend its participation at the air phase.

\section{Acknowledgments}

The authors would like to thank to the Turkish Government for a PhD scholarship, the European Research Council (Funding Scheme: ERC Starting Grant, 2010, Project Number 261152), and the Danish Strategic Research Council (DSF -10-93456) for financial support. We also thank to Anton Paar Nordic AB Malmö, Sweden (Parastoo Salavati and Jan B Petersen) for providing access to the interfacial Physica MCR 302 rheometer and for valuable discussions. 


\section{References}

[1] J.T. Petkov, T.D. Gurkov, B.E. Campbell, R.P. Borwankar, Dilatational and shear elasticity of gel-like protein layers on air/water interface, Langmuir. 16 (2000) 3703-3711.

[2] P. Cicuta, E.M. Terentjev, Viscoelasticity of a protein monolayer from anisotropic surface pressure measurements, Eur. Phys. J. E. 16 (2005) 147-158.

[3] P.A. Rühs, N. Scheuble, E.J. Windhab, P. Fischer, Simultaneous Control of pH and Ionic Strength during Interfacial Rheology of $\beta$ - Lactoglobulin Fibrils Adsorbed at Liquid / Liquid Interfaces, Langmuir. 28 (2012) 12536-12543.

[4] E. Dickinson, Adsorbed protein layers at fluid interfaces: Interactions, structure and surface rheology, Colloids Surfaces B Biointerfaces. 15 (1999) 161-176.

[5] R.N. Zúñiga, A. Tolkach, U. Kulozik, J.M. Aguilera, Kinetics of formation and physicochemical characterization of thermally-induced beta-Lactoglobulin aggregates, J. Food Sci. 75 (2010) 261-268.

[6] L. Shi, R. Ardehali, K.D. Caldwell, P. Valint, Mucin coating on polymeric material surfaces to suppress bacterial adhesion, Colloids Surfaces B Biointerfaces. 17 (2000) 229-239.

[7] R. Bansil, B.S. Turner, Mucin structure, aggregation, physiological functions and biomedical applications, Curr. Opin. Colloid Interface Sci. 11 (2006) 164-170.

[8] H.Y. Çelebioğlu, M. Gudjónsdóttir, S. Meier, J.O. Duus, S. Lee, I.S. Chronakis, Spectroscopic studies of the interactions between beta-lactoglobulin and bovine submaxillary mucin, Food Hydrocoll. 50 (2015) 203-210.

[9] H.Y. Shrivastava, B.U. Nair, Structural modification and aggregation of mucin by 
chromium(III) complexes., J. Biomol. Struct. Dyn. 20 (2003) 575-87.

[10] H.Y. Çelebioğlu, M. Gudjónsdóttir, I.S. Chronakis, S. Lee, Investigation of the interaction between mucins and beta-lactoglobulin under tribological stress, Food Hydrocoll. 54 (2016) $57-65$.

[11] J. Krägel, S.R. Derkatch, Interfacial shear rheology, Curr. Opin. Colloid Interface Sci. 15 (2010) 246-255.

[12] E.H. Lucassen-Reynders, D.T. Wasan, Interfacial Viscoelasticity in Emulsions and Foams, Food Struct. 12 (1993) 1-12.

[13] D. Rossetti, G.E. Yakubov, J.R. Stokes, A.-M. Williamson, G.G. Fuller, Interaction of human whole saliva and astringent dietary compounds investigated by interfacial shear rheology, Food Hydrocoll. 22 (2008) 1068-1078.

[14] J. Maldonado-Valderrama, J.M.R. Patino, Interfacial rheology of protein-surfactant mixtures, Curr. Opin. Colloid Interface Sci. 15 (2010) 271-282.

[15] J.-M. Jung, D.Z. Gunes, R. Mezzenga, Interfacial activity and interfacial shear rheology of native $\beta$-lactoglobulin monomers and their heat-induced fibers., Langmuir. 26 (2010) 1536675.

[16] D.A. Kim, M. Cornec, G. Narsimhan, Effect of thermal treatment on interfacial properties of beta-lactoglobulin, J. Colloid Interface Sci. 285 (2005) 100-109.

[17] S. Roth, S. Roth, B.S. Murray, B.S. Murray, E. Dickinson, E. Dickinson, Interfacial sheer rheology of aged and heat-treated beta-lactoglobulin films: Displacement by nonionic surfactant, J. Agric. Food Chem. 48 (2000) 1491-1497. 
[18] J. Läuger, P. Heyer, Interfacial shear rheology of coffee samples, AIP Conf. Proc. 1027 (2008) 1057-1059. doi:10.1063/1.2964465.

[19] P. Erni, P. Fischer, E.J. Windhab, V. Kusnezov, H. Stettin, J. Läuger, Stress- and straincontrolled measurements of interfacial shear viscosity and viscoelasticity at liquid/liquid and gas/liquid interfaces, Rev. Sci. Instrum. 74 (2003) 4916-4924.

[20] J. Krägel, S.R. Derkatch, R. Miller, Interfacial shear rheology of protein-surfactant layers, Adv. Colloid Interface Sci. 144 (2008) 38-53.

[21] R. Wüstneck, J. Krägel, R. Miller, V.B. Fainerman, P.J. Wilde, D.K. Sarker, D.C. Clark, Dynamic surface tension and adsorption properties of b-casein and b-lactoglobulin, Food Hydrocoll. 10 (1996) 395-405.

[22] J. Krägel, M. Bree, R. Wüstneck, A. V. Makievski, D.O. Grigoriev, O. Senkel, R. Miller, V.B. Fainerman, Dynamics and thermodynamics of spread and adsorbed food protein layers at the water/air interface, Mol. Nutr. Food Res. 42 (1998) 229-231.

[23] R. Miller, J. Kragel, R. Wustneck, P.J. Wilde, J.B. Li, V.B. Fainerman, G. Loglio, a W. Neumann, Adsorption kinetics and rheological properties of food proteins at air/water and oil/water interfaces, Mol. Nutr. Food Res. 42 (1998) 225-228.

[24] H. Pessen, J.M. Purcell, H.M. Farrell, Proton relaxation rates of water in dilute solutions of beta-lactoglobulin. Determination of cross relaxation and correlation with structural changes by the use of two genetic variants of a self-associating globular protein, Biochim. Biophys. Acta (BBA)/Protein Struct. Mol. 828 (1985) 1-12.

[25] N. Taulier, T. V Chalikian, Characterization of $\mathrm{pH}$-induced transitions of beta-lactoglobulin: ultrasonic, densimetric, and spectroscopic studies., J. Mol. Biol. 314 (2001) 873-889. 
[26] H. Hägerström, M. Paulsson, K. Edsman, Evaluation of mucoadhesion for two polyelectrolyte gels in simulated physiological conditions using a rheological method, Eur. J. Pharm. Sci. 9 (2000) 301-309.

[27] E. Dickinson, Faraday research article. Structure and composition of adsorbed protein layers and the relationship to emulsion stability, J. Chem. Soc. Faraday Trans. 88 (1992) 2973.

[28] K.D. Danov, P.A. Kralchevsky, G.M. Radulova, E.S. Basheva, S.D. Stoyanov, E.G. Pelan, Shear rheology of mixed protein adsorption layers vs their structure studied by surface force measurements, Adv. Colloid Interface Sci. 222 (2015) 148-161.

[29] J.F. Steffe, Rheological methods in food process engineering. Freeman press, Freeman press, 1996. 


\section{Tables}

Table 1. The rate of frequency dependent change in viscoelastic moduli of BLG, BSM and the BLG-BSM mixture at $\mathrm{pH} 7.4,5.0$, and 3.0. Two different concentrations for the mixture were used. MIX 1 and MIX 2 represent $1 \mathrm{mg} / \mathrm{mL}$ and $2 \mathrm{mg} / \mathrm{mL}$ concentration, respectively. The data fit to power law equation: $G_{i}{ }^{\prime}=k^{\prime} \omega^{m^{\prime}}$ and $G_{i}{ }^{\prime \prime}=k^{\prime \prime} \omega^{m^{\prime \prime}}$ where the values of constants $k^{\prime}$ and $k^{\prime \prime}$ and slopes $m^{\prime}$ and $m^{\prime \prime}$. Frequency range was from 0.01 to $10 \mathrm{rad} / \mathrm{s}$.

* slope was calculated in frequency range of $0.02-0.06 \mathrm{rad} / \mathrm{s}$

\begin{tabular}{llllrl} 
& & \multicolumn{2}{c}{ constant } & \multicolumn{2}{c}{ slope } \\
pH & sample & $\boldsymbol{k}^{\prime}$ & $\boldsymbol{k}^{\prime \prime}$ & $\boldsymbol{m}^{\prime}$ & $\boldsymbol{m}^{\prime \prime}$ \\
& BLG & 0.033 & 0.008 & 0.136 & 0.042 \\
7.4 & BSM & 0.010 & 0.002 & ${ }^{*} 0.081$ & 0.196 \\
& MIX 1 & 0.015 & 0.005 & 0.072 & 0.041 \\
& MIX 2 & 0.018 & 0.004 & 0.077 & 0.062 \\
& & & & & \\
& BLG & 0.108 & 0.020 & 0.122 & 0.004 \\
5.0 & BSM & 0.008 & 0.002 & 0.013 & 0.210 \\
& MIX 1 & 0.055 & 0.011 & 0.139 & 0.042 \\
& MIX 2 & 0.037 & 0.009 & 0.116 & 0.060 \\
& & & & & \\
& BLG & 0.027 & 0.005 & 0.100 & 0.030 \\
3.0 & BSM & 0.007 & 0.001 & 0.016 & 0.228 \\
& MIX 1 & 0.015 & 0.004 & 0.060 & 0.087 \\
& MIX 2 & 0.008 & 0.002 & 0.070 & 0.117
\end{tabular}


Table 2. The rate of strain dependent decrease in viscoelastic moduli of BLG and the BLG-BSM mixture at $\mathrm{pH} 7.4,5.0$, and 3.0 after the breaking of the sample structure. Two different concentrations for the mixture were used. MIX 1 and MIX 2 represent $1 \mathrm{mg} / \mathrm{mL}$ and $2 \mathrm{mg} / \mathrm{mL}$ concentration, respectively. The data fit to power law equation: $G_{i}{ }^{\prime}=c^{\prime} \gamma^{n^{\prime}}$ and $G_{i}{ }^{\prime \prime}=c^{\prime \prime} \gamma^{n^{\prime \prime}}$ where the values of constants $c^{\prime}$ and $c^{\prime \prime}$ and slopes $n^{\prime}$ and $n^{\prime \prime}$

\begin{tabular}{llllll} 
& & \multicolumn{2}{c}{ constant } & \multicolumn{2}{c}{ slope } \\
pH & sample & $c^{\prime}$ & $c^{\prime \prime}$ & $n^{\prime}$ & $n^{\prime \prime}$ \\
& BLG & 0.220 & 0.023 & -1.223 & -0.514 \\
7.4 & MIX 1 & 0.113 & 0.006 & -1.165 & -0.316 \\
& MIX 2 & 0.098 & 0.013 & -1.297 & -0.450 \\
& & & & & \\
& BLG & 1.181 & 0.144 & -2.062 & -0.806 \\
5.0 & MIX 1 & 0.594 & 0.070 & -1.862 & -0.724 \\
& MIX 2 & 0.223 & 0.037 & -1.265 & -0.593 \\
& & & & & \\
& BLG & 0.297 & 0.035 & -1.986 & -0.714 \\
3.0 & MIX 1 & 0.307 & 0.008 & -1.953 & -0.415 \\
& MIX 2 & 0.001 & 0.003 & -0.666 & -0.201
\end{tabular}


Table 3. Crossover points

\begin{tabular}{llr}
\multicolumn{2}{c}{ Crossover point } \\
pH & sample & Strain (\%) (ca.) \\
& BLG & 25.00 \\
7.4 & BSM & 0.05 \\
& MIX 1 & 37.00 \\
& MIX 2 & 13.00 \\
& & \\
& BLG & 6.00 \\
5.0 & BSM & 0.06 \\
& MIX 1 & 8.00 \\
& MIX 2 & 19.00 \\
& & \\
& BLG & 6.00 \\
3.0 & BSM & 0.06 \\
& MIX 1 & 12.00 \\
& MIX 2 & 0.40
\end{tabular}




\section{Figure captions}

Fig. 1. Time sweep for $1 \mathrm{mg} / \mathrm{mL}$ BLG, BSM and the BLG-BSM mixtures at (a) $\mathrm{pH} 7.4$, (b) $\mathrm{pH}$ 5.0, and (c) $\mathrm{pH}$ 3.0. Two different concentrations for the mixture were used. MIX 1 and MIX 2 represent $1 \mathrm{mg} / \mathrm{mL}$ and $2 \mathrm{mg} / \mathrm{mL}$ concentration, respectively.

Fig. 2. (a) Elastic modulus and (b) viscous modulus of BLG, BSM, the BLG-BSM mixtures, and calculated interaction terms $\Delta G_{i}{ }^{\prime}$ and $\Delta G_{i}{ }^{\prime}$. Two different concentrations for the mixture were used. MIX 1 and MIX 2 represent $1 \mathrm{mg} / \mathrm{mL}$ and $2 \mathrm{mg} / \mathrm{mL}$ concentration, respectively. All samples were prepared in phosphate buffer. Values shown correspond to the frequency of $6.28 \mathrm{rad} / \mathrm{s}$ and strain of $0.02 \%$.

Fig. 3. Illustration of the interactions of hydrophobic patches of BSM with the adsorbed BLG layer at (a) $\mathrm{pH} 7.4$, (b) $\mathrm{pH} 5.0$ and (c) $\mathrm{pH} 3.0$.

Fig. 4. Frequency dependence of BLG and the BSM-BLG mixtures at (a) $\mathrm{pH} 7.4$, (b) $\mathrm{pH} 5.0$, and (c) $\mathrm{pH}$ 3.0. Two different concentrations for the mixture were used. MIX 1 and MIX 2 represent 1 $\mathrm{mg} / \mathrm{mL}$ and $2 \mathrm{mg} / \mathrm{mL}$ concentration, respectively. The data fit to power law equation: $G_{i}^{\prime}=k^{\prime} \omega^{m^{\prime}}$ and $G_{i}^{\prime \prime}=k^{\prime \prime} \omega^{m "}$ where the values of constants $k^{\prime}$ and $k^{\prime \prime}$ and slopes $m^{\prime}$ and $m^{\prime \prime}$ are shown in Table 1 .

Fig. 5. Interfacial complex viscosity (blue) and interfacial steady-shear viscosity (red) of BLG, BSM, and the BLG-BSM mixtures (a) $\mathrm{pH} 7.4$, (b) $\mathrm{pH} 5.0$, and (c) $\mathrm{pH}$ 3.0. Two different concentrations for the mixture were used. MIX 1 and MIX 2 represent $1 \mathrm{mg} / \mathrm{mL}$ and $2 \mathrm{mg} / \mathrm{mL}$ concentration, respectively.

Fig. 6. Strain sweep for $1 \mathrm{mg} / \mathrm{mL}$ BLG, BSM and the BLG-BSM mixtures at (a) pH 7.4, (b) pH 5.0, and (c) $\mathrm{pH}$ 3.0. Values shown correspond to the frequency of $6.28 \mathrm{rad} / \mathrm{s}$. Two different 
concentrations for the mixture were used. MIX 1 and MIX 2 represent $1 \mathrm{mg} / \mathrm{mL}$ and $2 \mathrm{mg} / \mathrm{mL}$ concentration, respectively. The rate of strain dependent decrease in viscoelastic moduli of protein samples after the breaking of the sample structure fit to power law equation: $G^{\prime}=c^{\prime} \gamma^{n^{\prime}}$ and $G^{\prime \prime}=c^{\prime \prime} \gamma^{n^{\prime \prime}}$ where the values of constants $c^{\prime}$ and $c^{\prime \prime}$ and slopes $n^{\prime}$ and $n^{\prime \prime}$ are shown in Table 2 .

Fig. 7. Strain dependence of loss tangent $\left(\tan \delta_{i}\right)$ of BSM, BLG and the BSM-BLG mixtures at (a) pH 7.4, (b) pH 5.0, and (c) pH 3.0. Two different concentrations for the mixture were used. MIX 1 and MIX 2 represent $1 \mathrm{mg} / \mathrm{mL}$ and $2 \mathrm{mg} / \mathrm{mL}$ concentration 


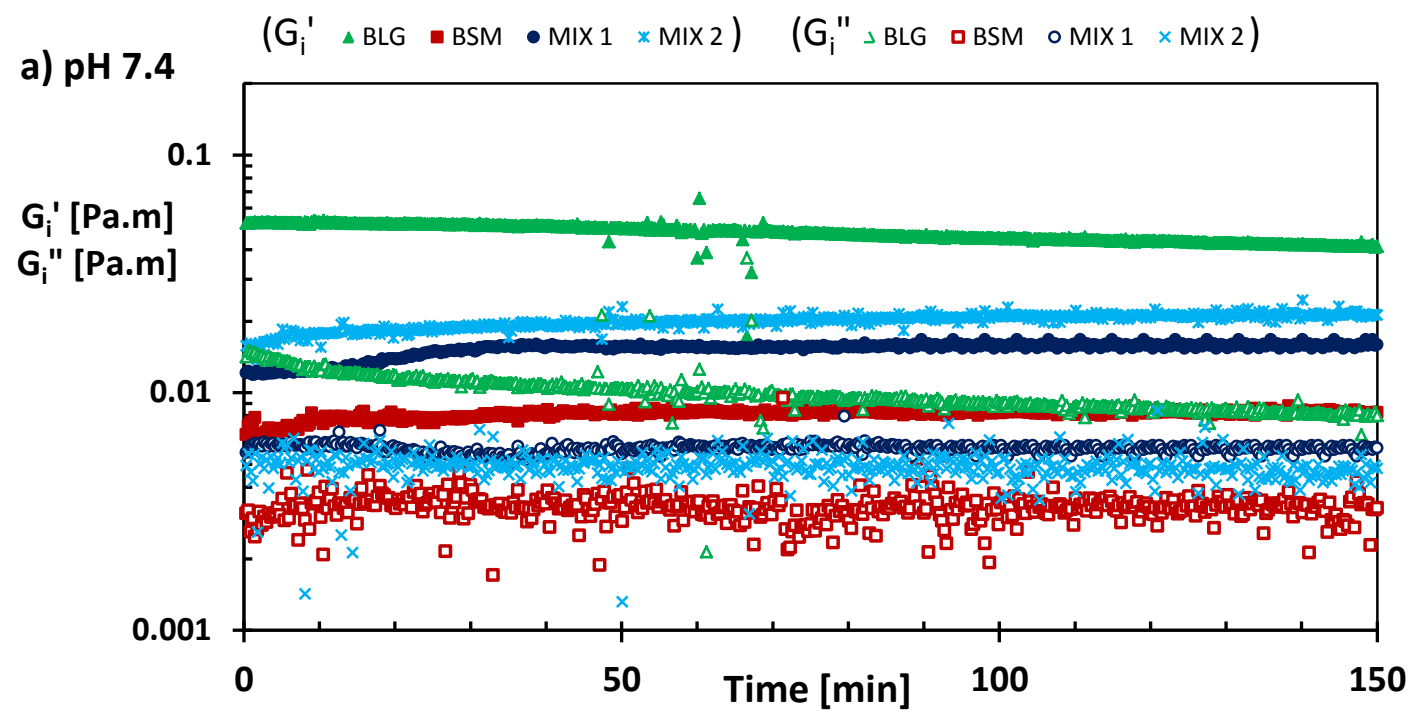

Fig. 1a 


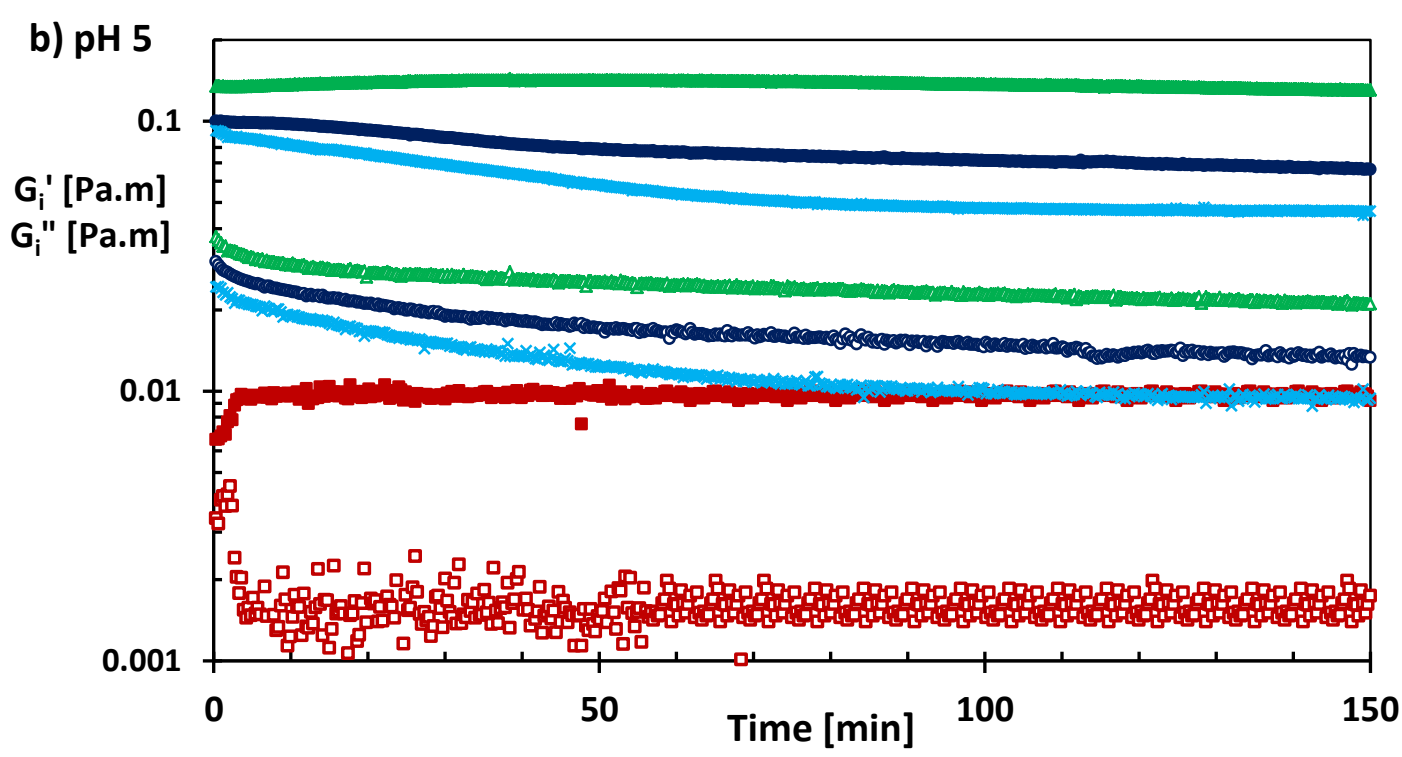

Fig. 1b 


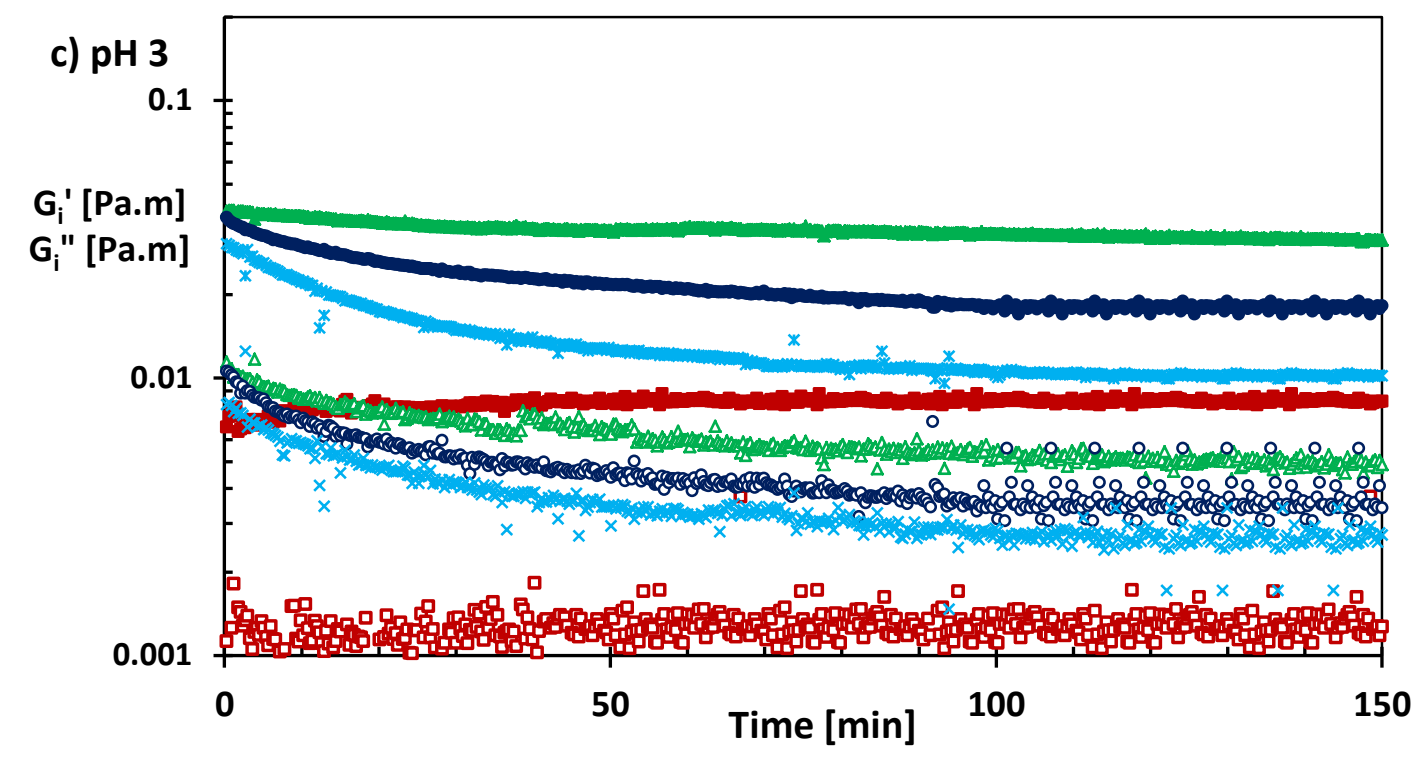

Fig. 1c

Fig. 1. Time sweep for $1 \mathrm{mg} / \mathrm{mL}$ BLG, BSM and the BLG-BSM mixtures at (a) $\mathrm{pH}$ 7.4, (b) $\mathrm{pH}$ 5.0, and (c) pH 3.0. Two different concentrations for the mixture were used. MIX 1 and MIX 2 represent $1 \mathrm{mg} / \mathrm{mL}$ and $2 \mathrm{mg} / \mathrm{mL}$ concentration, respectively. 


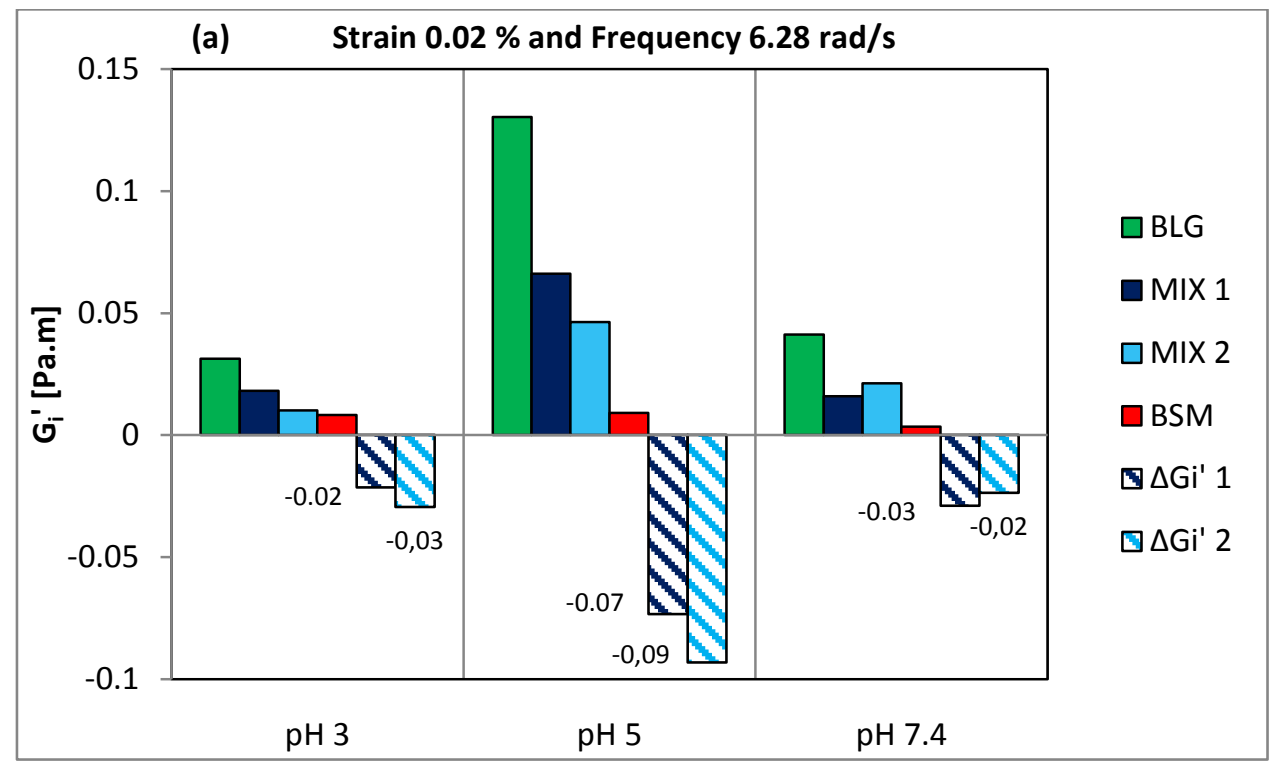

Fig. 2a 


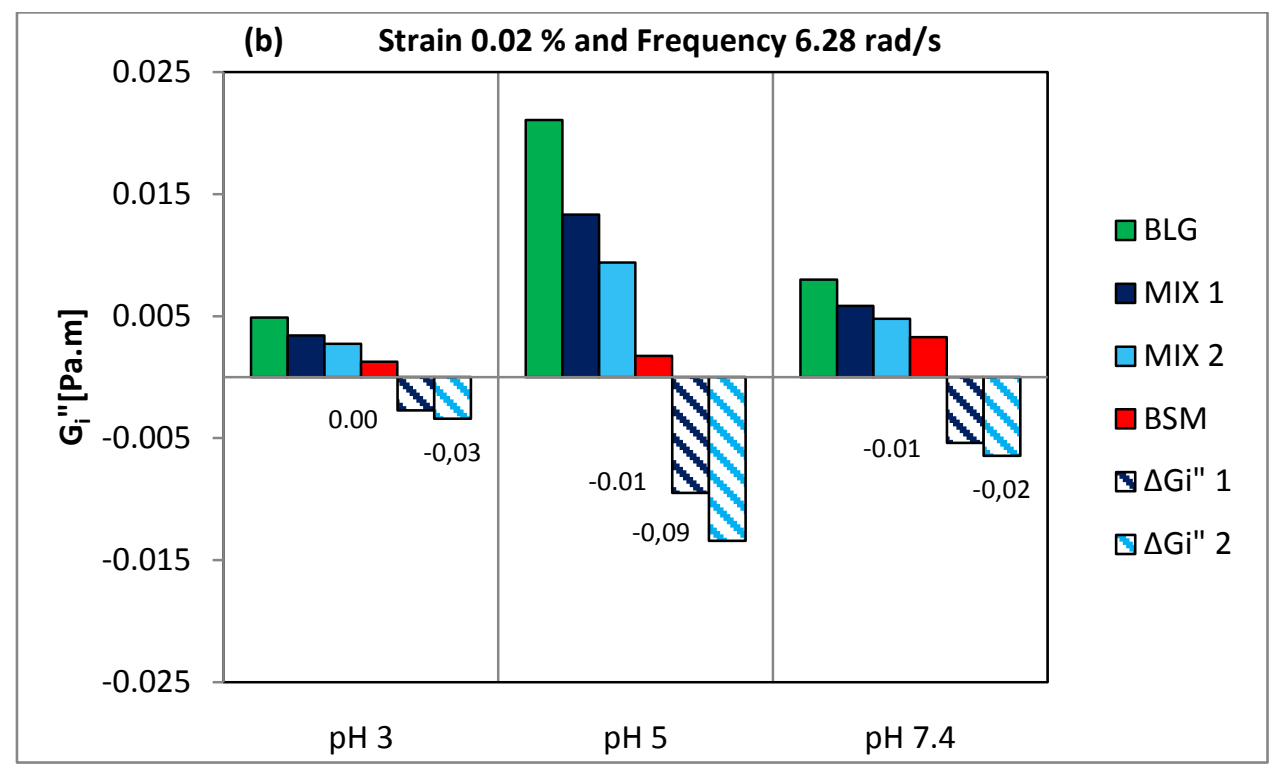

Fig. $2 b$

Fig. 2. (a) Elastic modulus and (b) viscous modulus of BLG, BSM, the BLG-BSM mixtures, and calculated interaction terms $\Delta G_{i}$ ' and $\Delta G_{i}$ ". Two different concentrations for the mixture were used. MIX 1 and MIX 2 represent $1 \mathrm{mg} / \mathrm{mL}$ and $2 \mathrm{mg} / \mathrm{mL}$ concentration, respectively. All samples were prepared in phosphate buffer. Values shown correspond to the frequency of $6.28 \mathrm{rad} / \mathrm{s}$ and strain of $0.02 \%$. 
Fig.3.

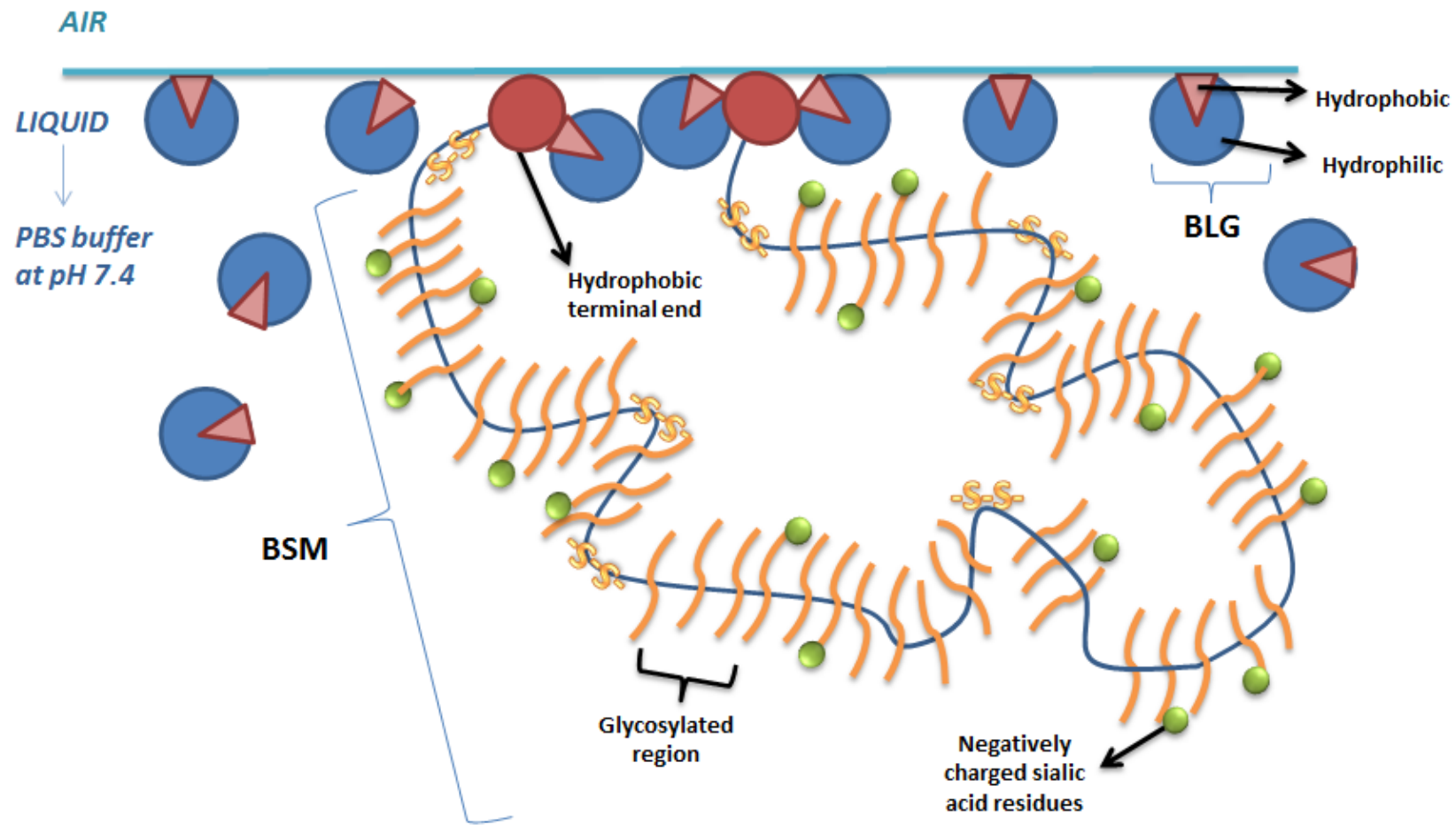

AIR

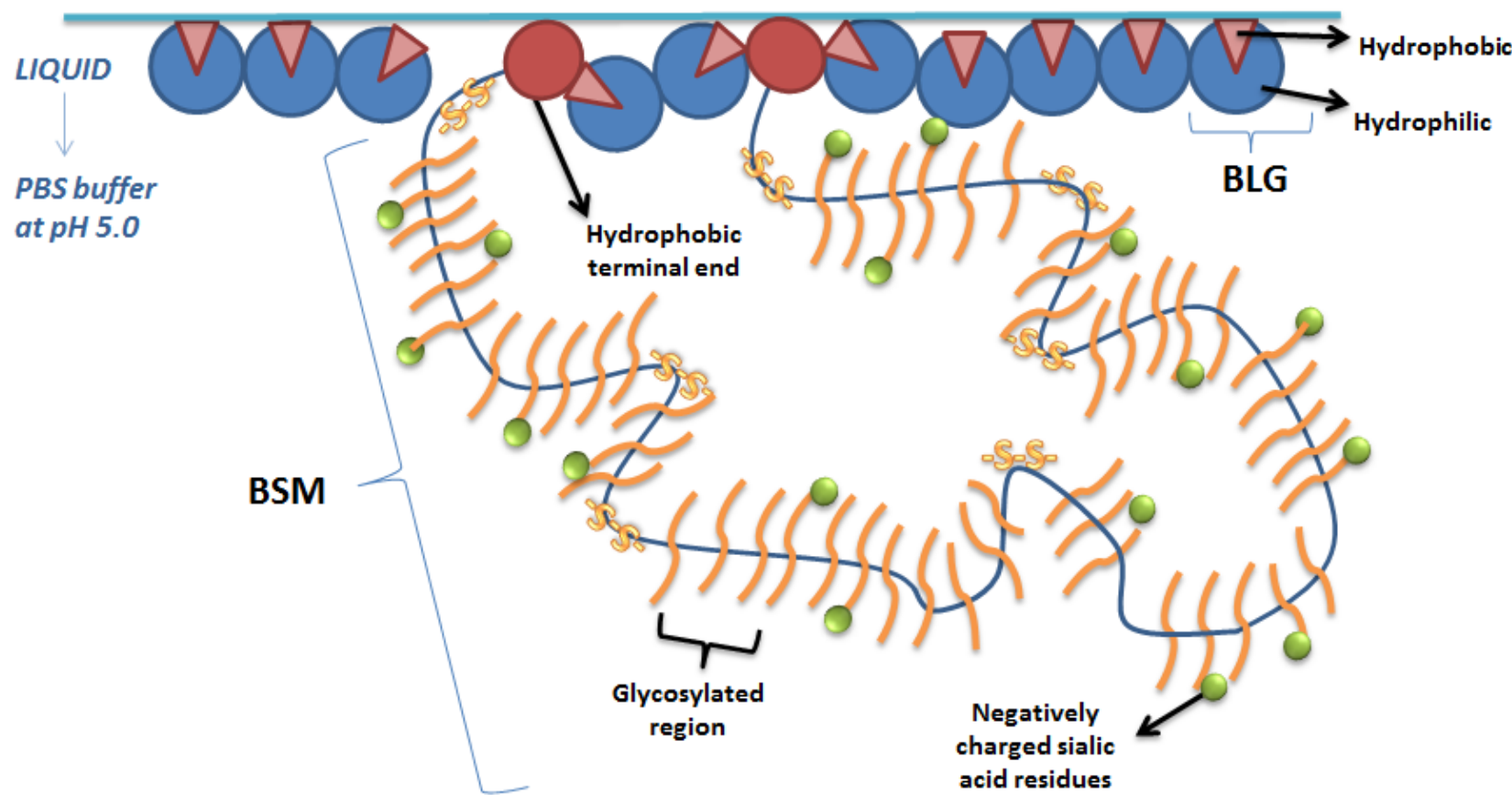




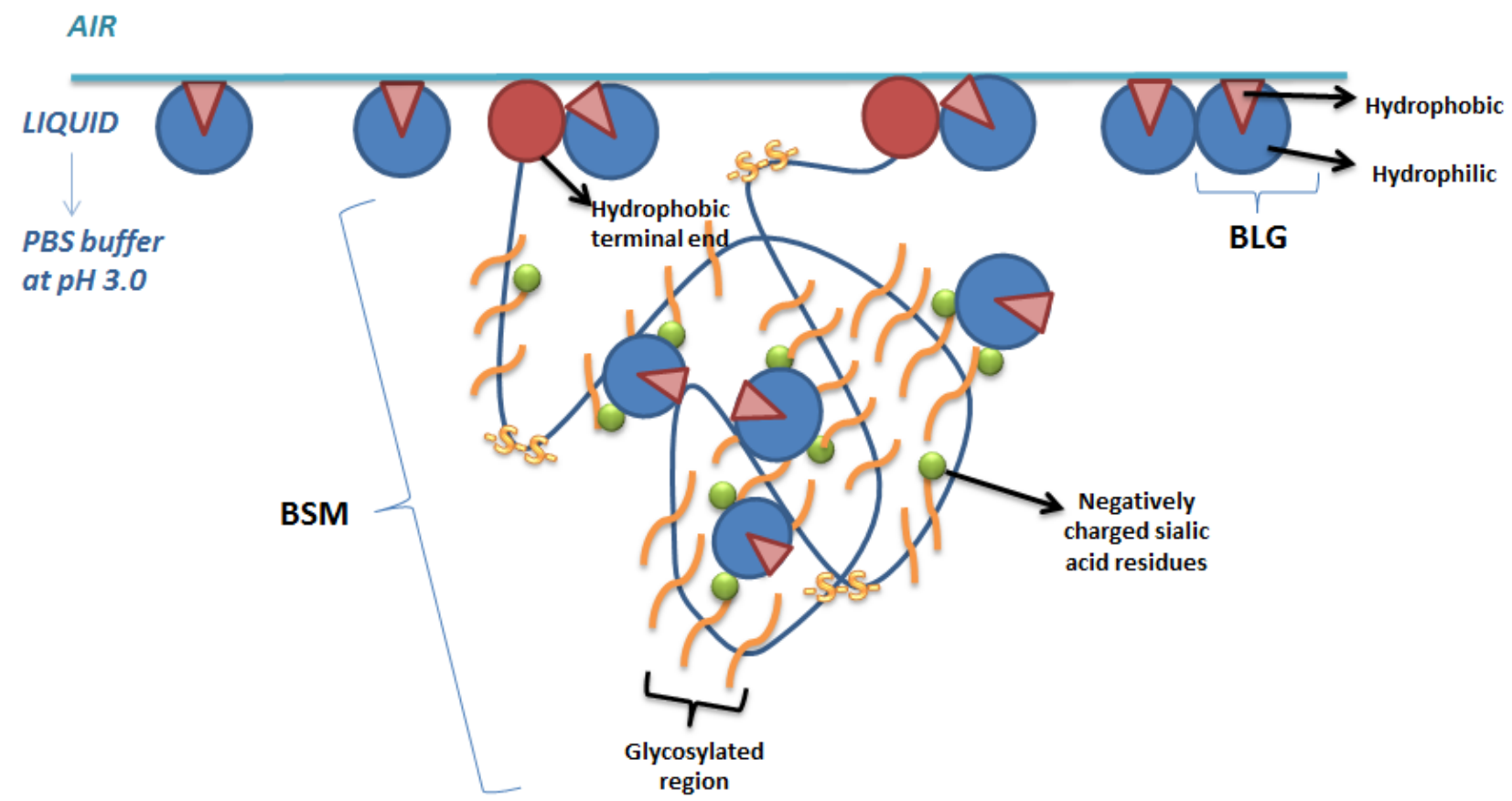

Fig. 3. Illustration of the interactions of hydrophobic patches of BSM with the adsorbed BLG layer at (a) pH 7.4, (b) pH 5.0 and (c) pH 3.0. 


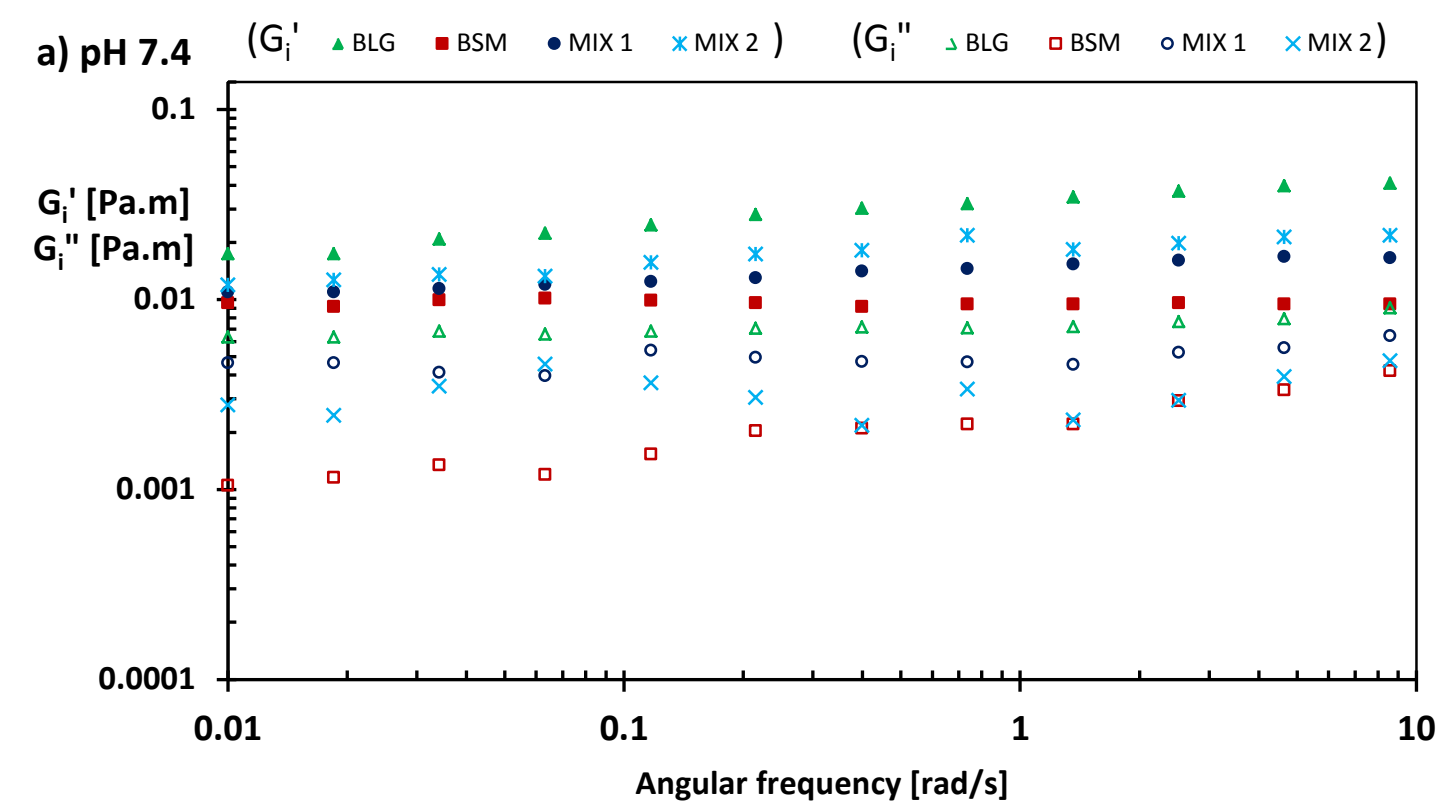

Fig. 4a 


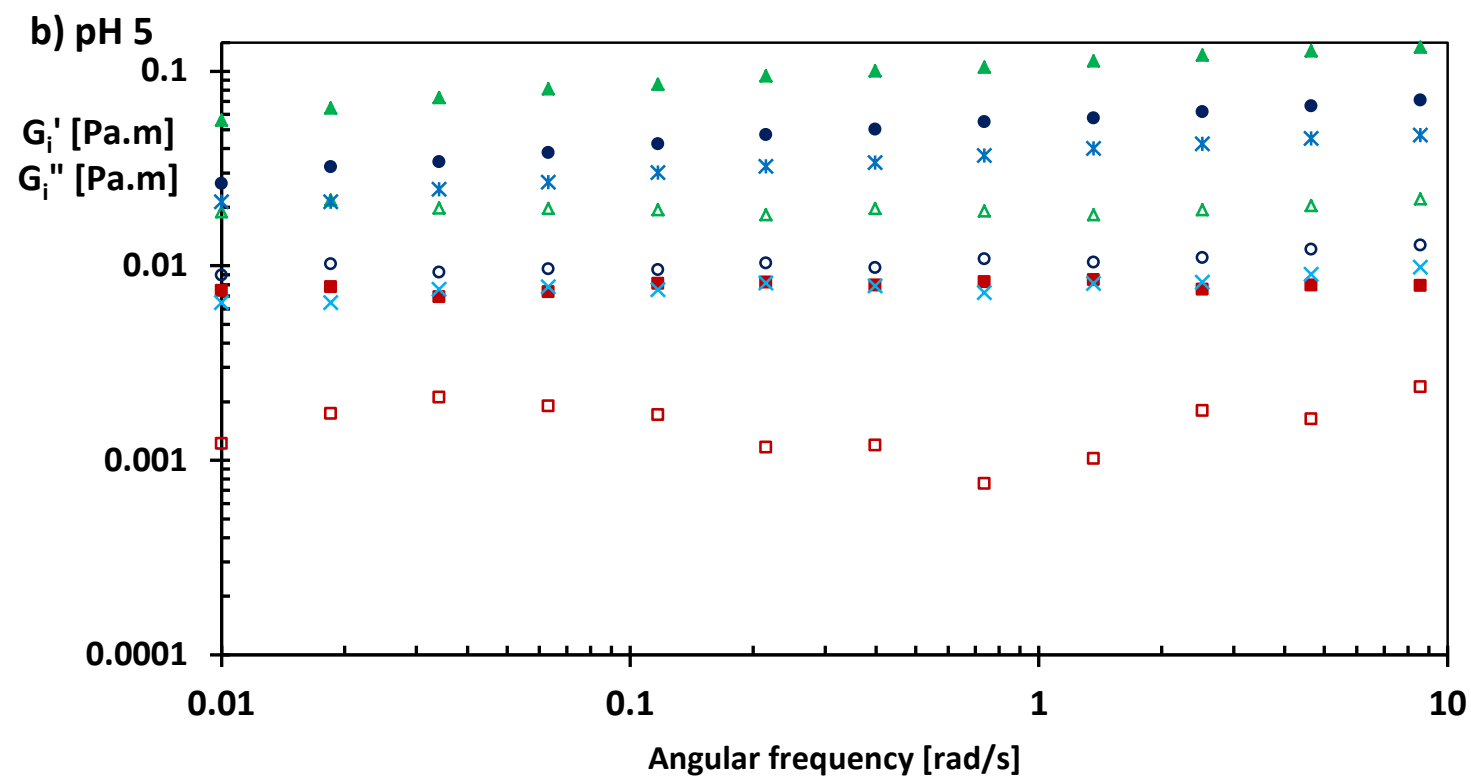

Fig. $4 b$ 


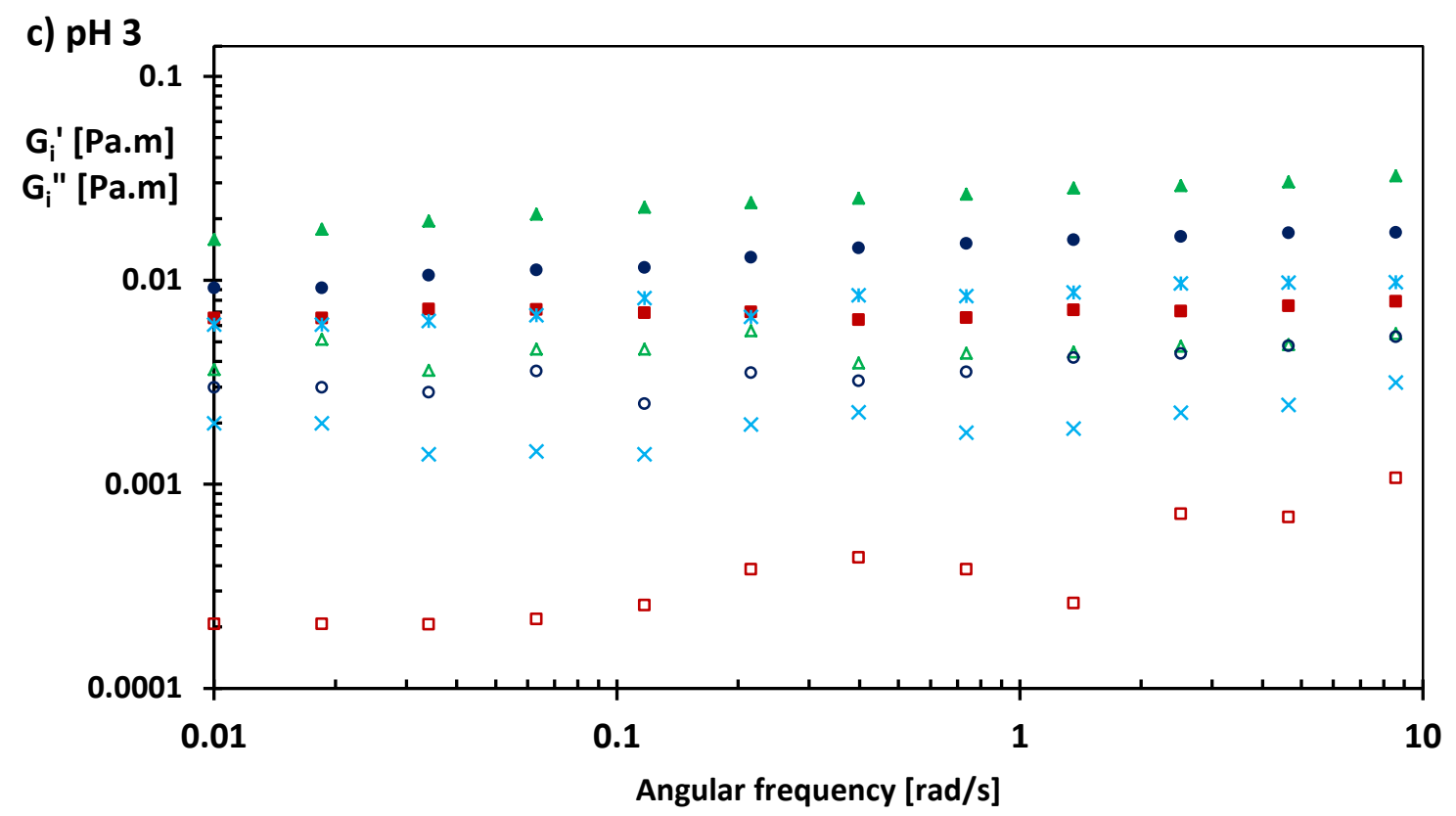

Fig. $4 \mathrm{C}$

Fig. 4. Frequency dependence of BLG and the BSM-BLG mixtures at (a) $\mathrm{pH} 7.4$, (b) $\mathrm{pH} 5.0$, and (c) $\mathrm{pH}$ 3.0. Two different concentrations for the mixture were used. MIX 1 and MIX 2 represent 1 $\mathrm{mg} / \mathrm{mL}$ and $2 \mathrm{mg} / \mathrm{mL}$ concentration, respectively. The data fit to power law equation: $G_{i}^{\prime}=k^{\prime} \omega^{m^{\prime}}$ and $G_{i}^{\prime \prime}=k^{\prime \prime} \omega^{m^{\prime \prime}}$ where the values of constants $k^{\prime}$ and $k^{\prime \prime}$ and slopes $m^{\prime}$ and $m^{\prime \prime}$ are shown in Table 1 . 


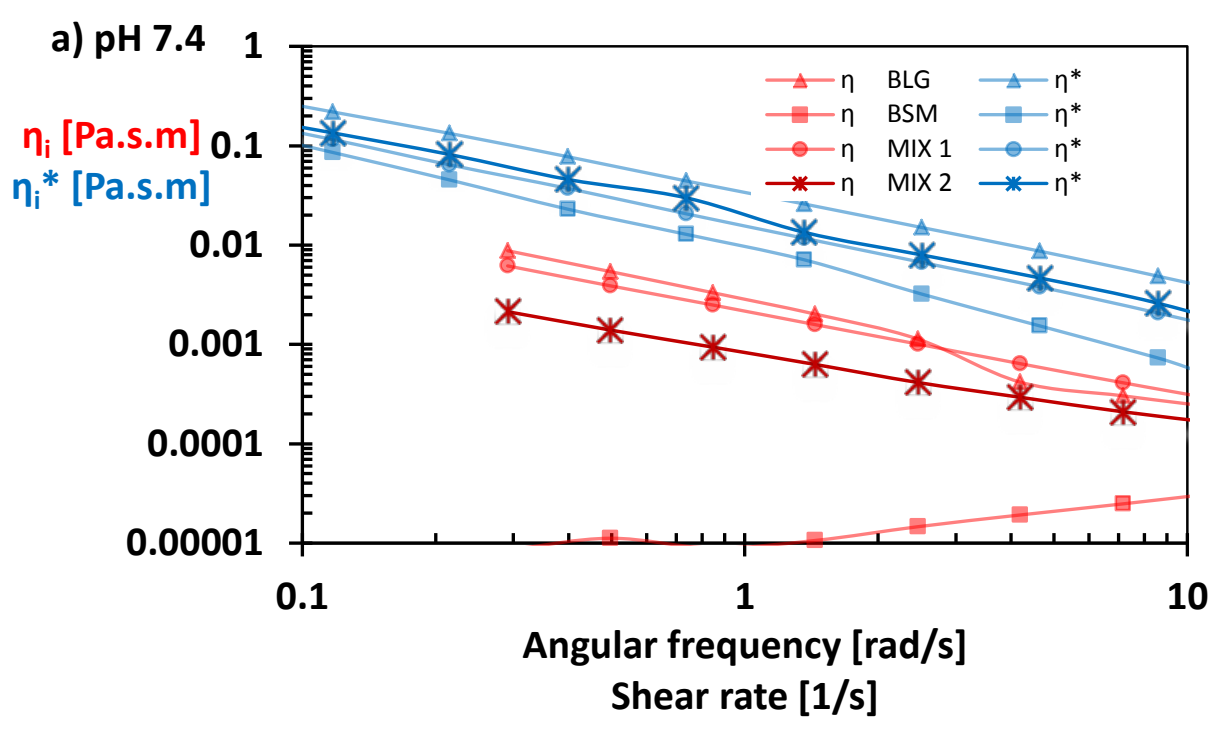

Fig. $5 a$ 


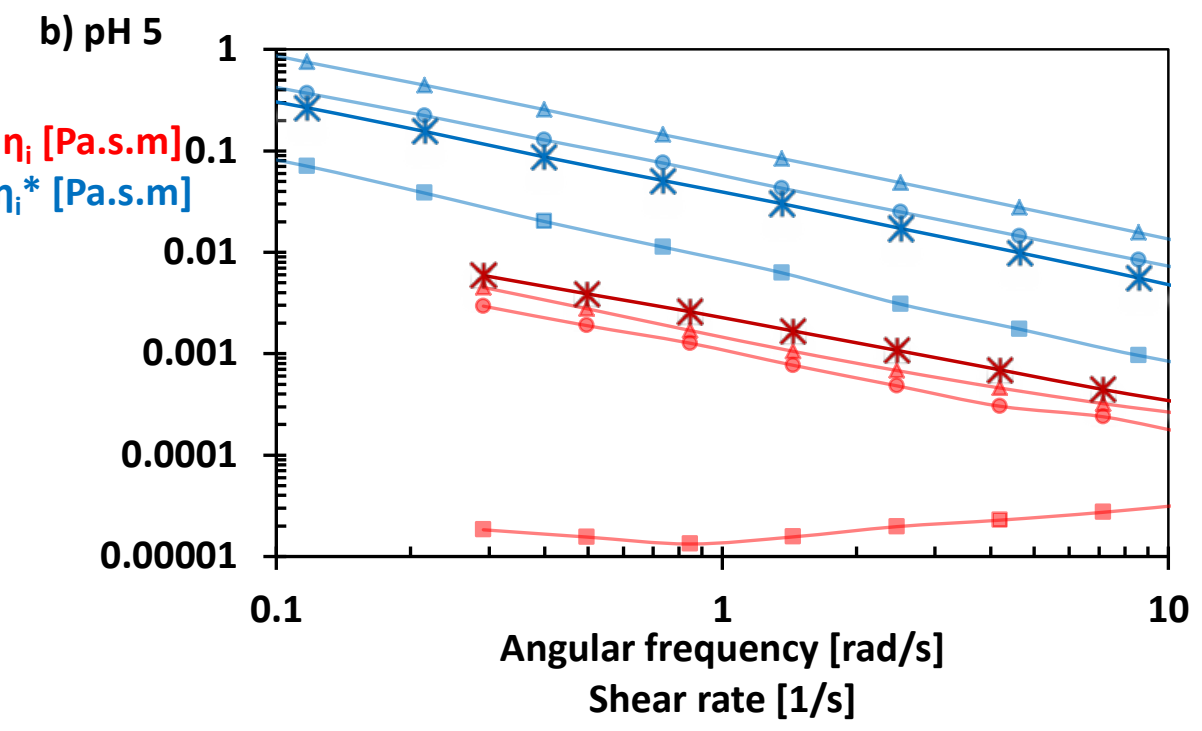

Fig. 5b 


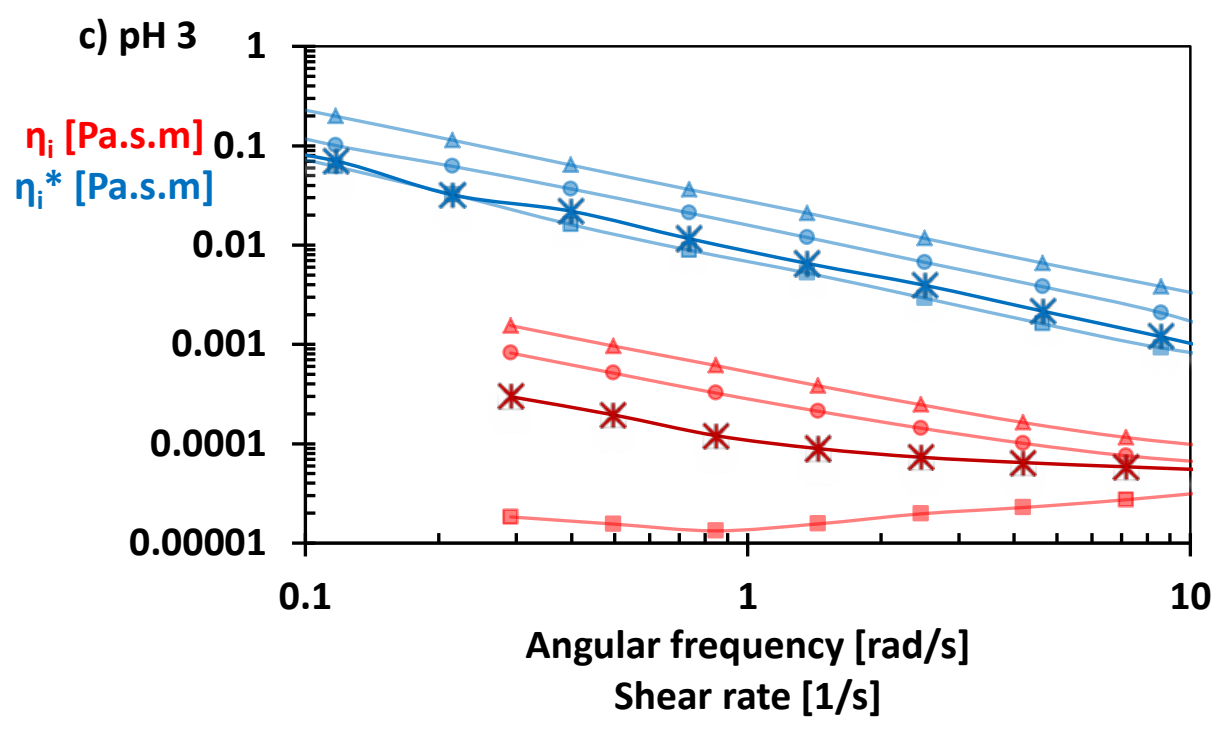

Fig. 5c

Fig. 5. Interfacial complex viscosity (blue) and interfacial steady-shear viscosity (red) of BLG, BSM, and the BLG-BSM mixtures (a) $\mathrm{pH} 7.4$, (b) $\mathrm{pH} 5.0$, and (c) $\mathrm{pH}$ 3.0. Two different concentrations for the mixture were used. MIX 1 and MIX 2 represent $1 \mathrm{mg} / \mathrm{mL}$ and $2 \mathrm{mg} / \mathrm{mL}$ concentration, respectively. 


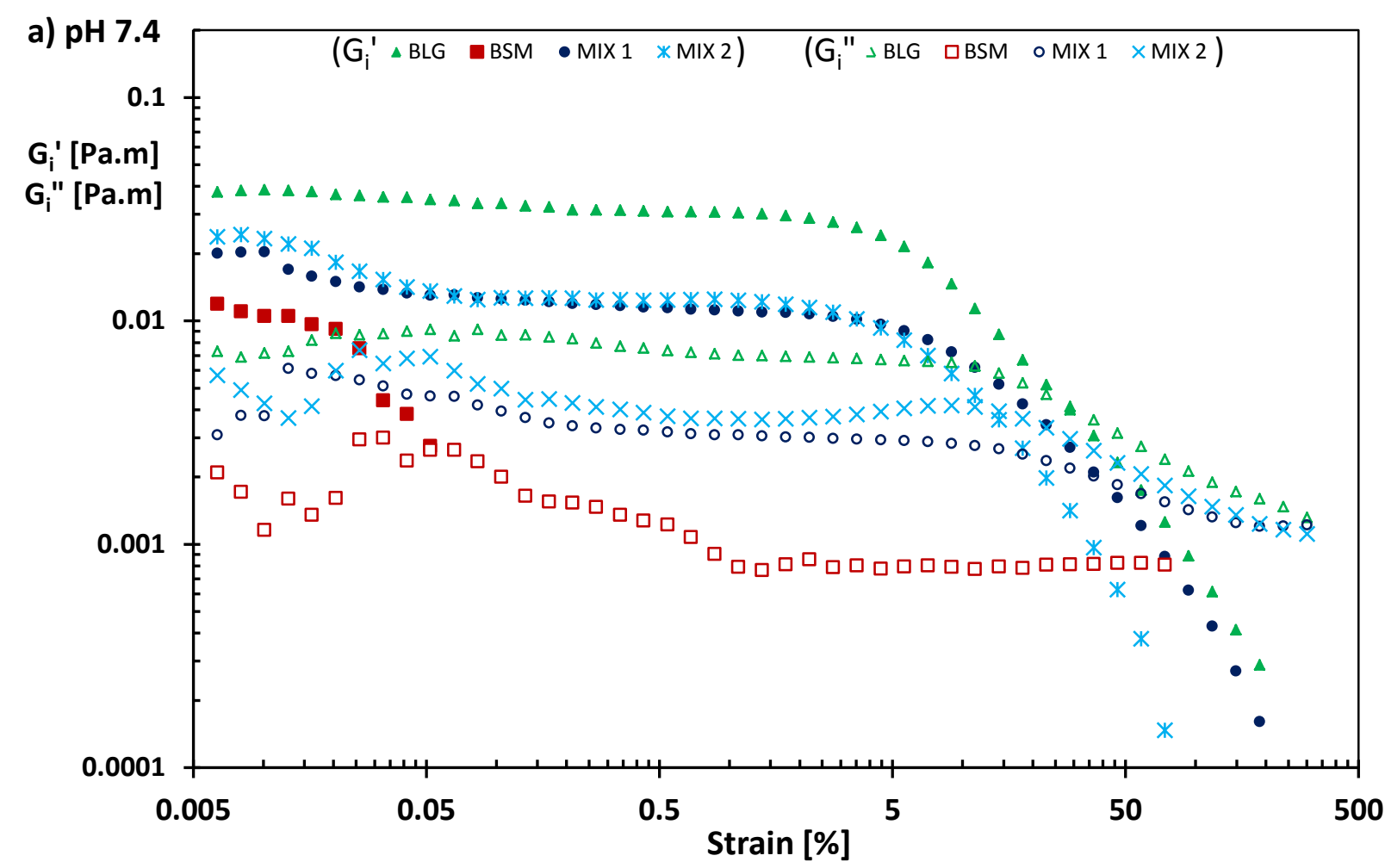

Fig. $6 a$ 
b) $\mathrm{pH} 5$

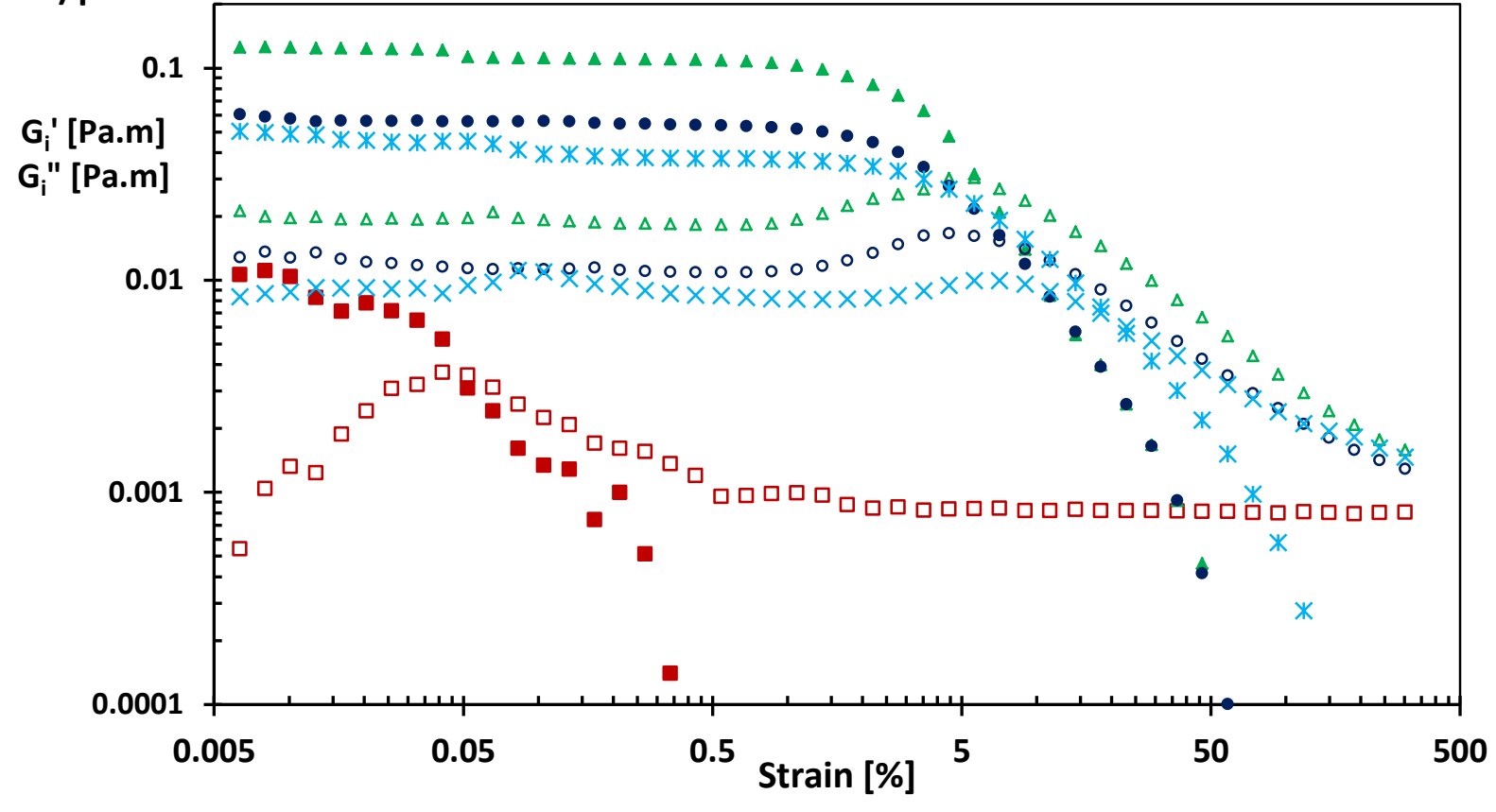

Fig. $6 b$ 


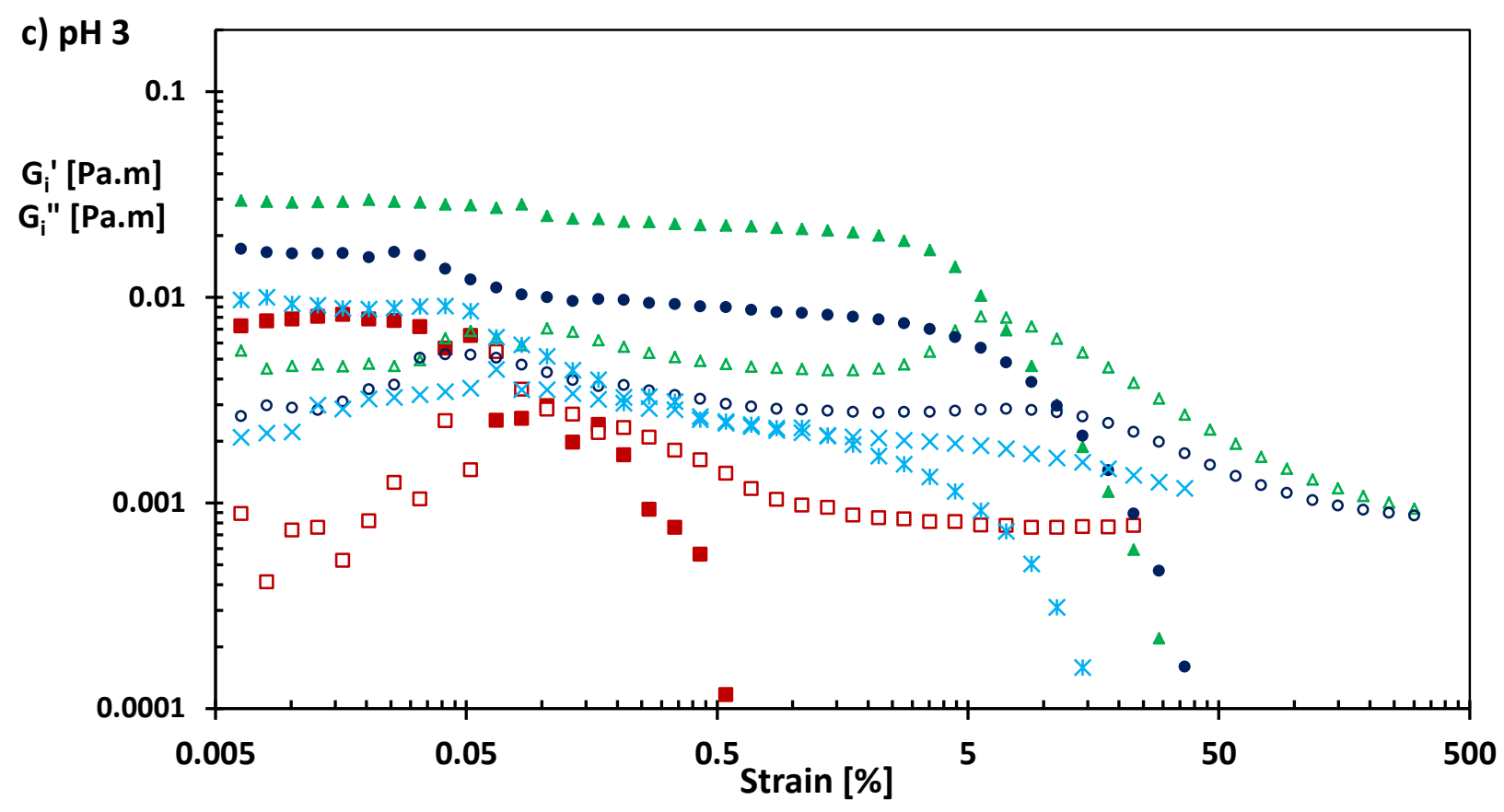

Fig. $6 c$

Fig. 6. Strain sweep for $1 \mathrm{mg} / \mathrm{mL}$ BLG, BSM and the BLG-BSM mixtures at (a) pH 7.4, (b) pH 5.0, and (c) $\mathrm{pH}$ 3.0. Values shown correspond to the frequency of $6.28 \mathrm{rad} / \mathrm{s}$. Two different concentrations for the mixture were used. MIX 1 and MIX 2 represent $1 \mathrm{mg} / \mathrm{mL}$ and $2 \mathrm{mg} / \mathrm{mL}$ concentration, respectively. The rate of strain dependent decrease in viscoelastic moduli of protein samples after the breaking of the sample structure fit to power law equation: $G^{\prime}=c^{\prime} \gamma^{n^{\prime}}$ and $G^{\prime \prime}=c^{\prime \prime} \gamma^{n "}$ where the values of constants $c^{\prime}$ and $c^{\prime \prime}$ and slopes $n^{\prime}$ and $n^{\prime \prime}$ are shown in Table 2. 


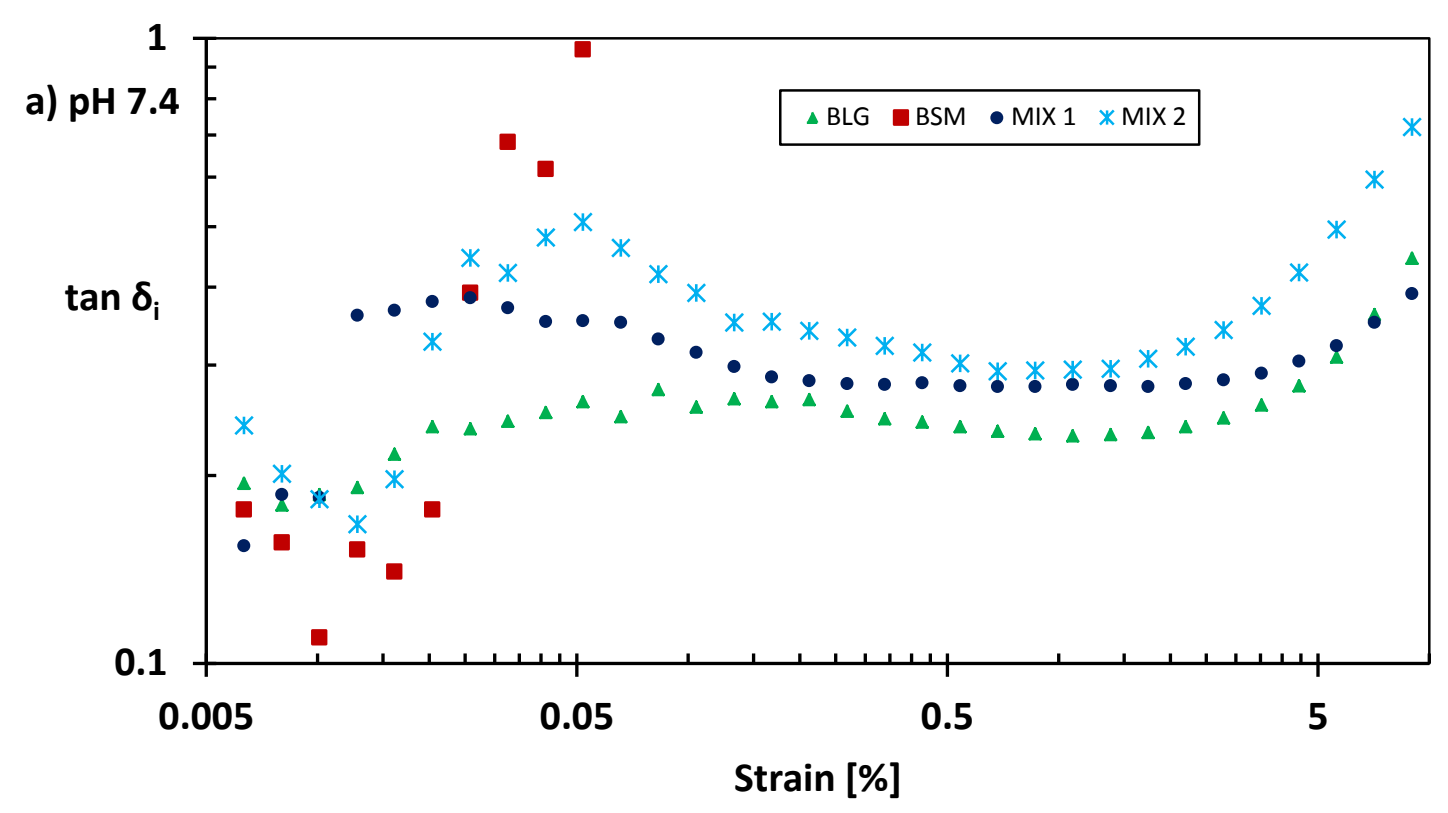

Fig. 7a 


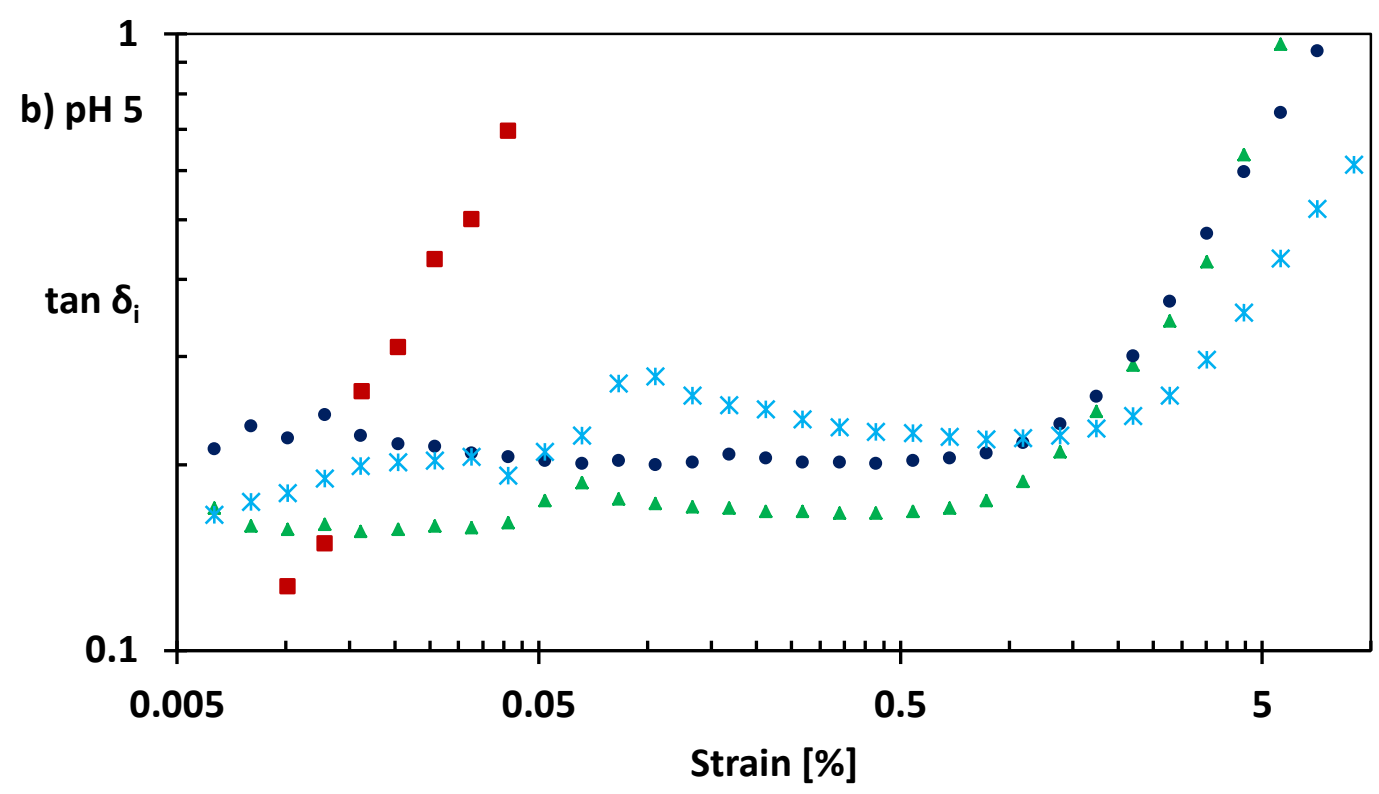

Fig. 7b 


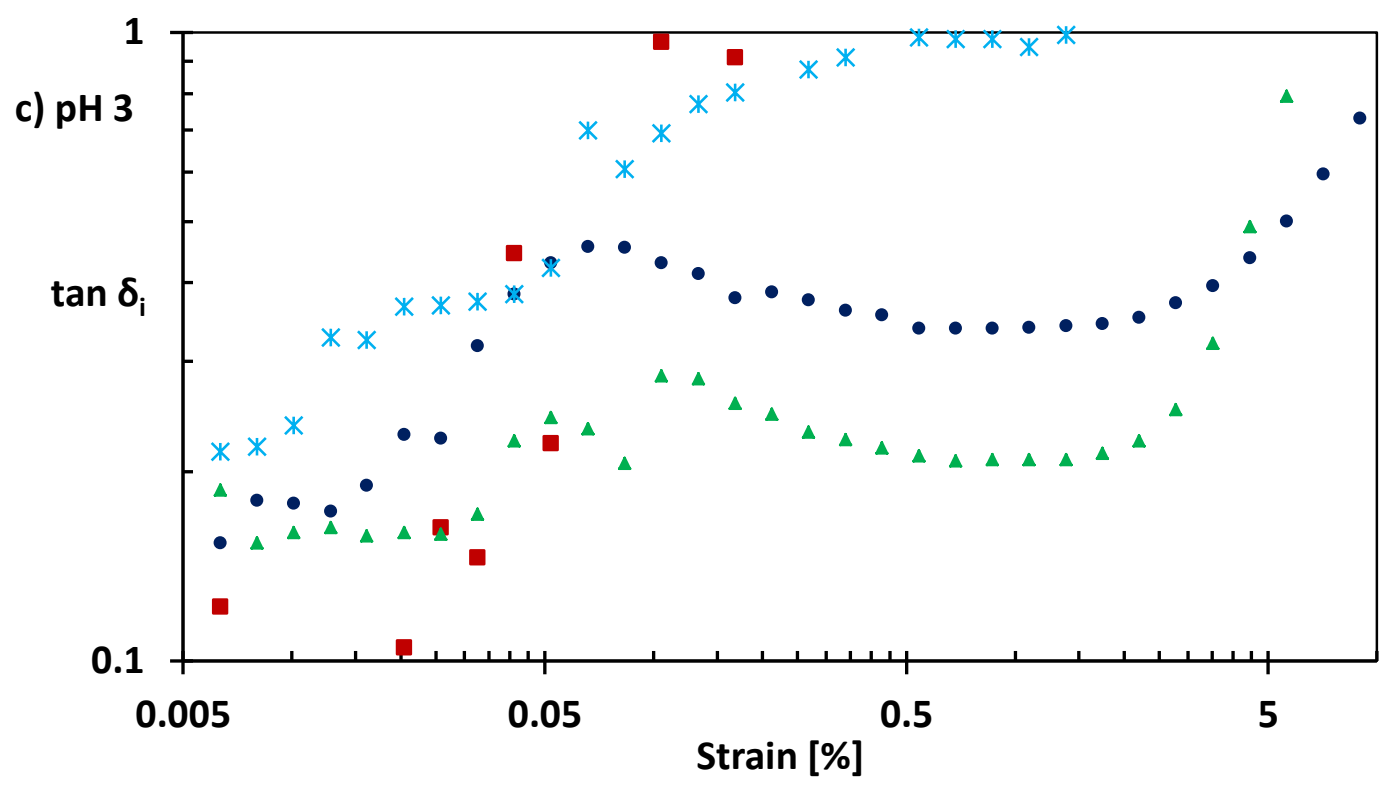

Fig. 7c

Fig. 7. Strain dependence of loss tangent ( $\tan \delta_{i}$ ) of BSM, BLG and the BSM-BLG mixtures at (a) $\mathrm{pH}$ 7.4, (b) pH 5.0, and (c) $\mathrm{pH}$ 3.0. Two different concentrations for the mixture were used. MIX 1 and MIX 2 represent $1 \mathrm{mg} / \mathrm{mL}$ and $2 \mathrm{mg} / \mathrm{mL}$ concentration 